\title{
Recaudar en los confines del imperio: impuestos y remesas en la Caja Real de Mendoza (Río de la Plata) a fines del período colonial 1779-1810
}

\author{
por \\ Antonio Facundo Galarza ${ }^{1}$ \\ CONICET/Cehis-Universidad Nacional de Mar del Plata
}

\begin{abstract}
El artículo presenta los resultados de la investigación realizada sobre la estructura tributaria de la Caja Real de Mendoza —Río de la Plata一, a fines del periodo colonial. Se indaga en la evolución de las recaudaciones de los diferentes impuestos, los suplementos y las transferencias recibidos por la hacienda regional. También se caracteriza la estructura de gastos. En particular, se presta especial atención al caudal de remesas que desde dicha Caja se enviaron a la tesorería general de Buenos Aires, a fin de estimar la capacidad de extracción de recursos de la Real Hacienda de la capital sobre las jurisdicciones del interior virreinal. Se pretende contribuir a caracterizar el relativo éxitolfracaso del sistema fiscal imperial a fines del siglo XVIII a la hora de recaudar impuestos y de asegurar las transferencias de remesas según las necesidades de la Monarquía española.
\end{abstract}

Palabras Clave: impuestos; remesas; Mendoza; Monarquía.

Cómo Citar este artículo / Citation: Galarza, Antonio Facundo, "Recaudar en los confines del imperio: impuestos y remesas en la Caja Real de Mendoza (Río de la Plata) a fines del período colonial, 1779-1810", Revista de Indias, LXXIX/276 (Madrid, 2019): 459-496. https://doi.org/10.3989/revindias.2019.014.

La organización fiscal del imperio español en América persiguió como fin, desde los tempranos tiempos de la conquista, extraer riquezas de sus colonias americanas y girar al menos una parte de las mismas hacia la metrópoli. La consecución de ese objetivo supuso para la Monarquía la lenta y trabajosa

\footnotetext{
1 afgcuervo@hotmail.com, ORCID iD: https://orcid.org/0000-0003-3803-3505.
} 
construcción de un esquema tributario a lo largo y a lo ancho de sus posesiones americanas. A fines del siglo XVIII, la Real Hacienda americana se organizaba a partir de tesorerías virreinales (México, Lima, Buenos Aires, Bogotá) que reunían bajo su órbita a un conjunto de cajas reales, a cargo de oficiales de hacienda, encargadas de la recolección impositiva en cada espacio regional. La teoría del funcionamiento tributario imperial indicaba que cada recaudación local debía servir en primera instancia para solventar los gastos propios, para luego enviar los saldos resultantes a la tesorería general del Virreinato. Una vez allí, el circuito finalizaba con el envío a la península de los fondos excedentes, una vez afrontados los gastos propios de la administración. De esta manera, el esquema preveía la autosuficiencia de las colonias, a la vez que proyectaba a éstas como una fuente de ingresos fiscales para las arcas metropolitanas.

Como desarrollaremos en detalle líneas abajo, la historiografía ha dedicado diversos estudios a la reconstrucción de los circuitos de traspasos de fondos, principalmente a partir de lo que consideramos tres líneas de investigación principales. En primer lugar, un tema clásico ha sido el de la reconstrucción del volumen de oro y la plata que las colonias americanas enviaron a la metrópoli española a lo largo del período colonial. En segundo lugar, el examen del sistema de subsidios conocidos como «situados»: transferencias de recursos entre grandes regiones al interior de las colonias, principalmente con objetivos de solventar gastos administrativos y militares. Por último, una línea de trabajo mucho menos explorada y en la cual se inserta nuestra investigación: el aporte de las diferentes cajas regionales a los fondos de las tesorerías generales de los virreinatos.

Estimar el caudal de fondos que las cajas regionales aportaron a la tesorería virreinal - rioplatense en nuestro caso - implica responder a la pregunta acerca de la capacidad de extracción de recursos que la Real Hacienda mostró a fines del período colonial en sus jurisdicciones americanas. Es decir, evaluar el relativo éxito/fracaso del sistema tributario - y de su reforma- a la hora de organizar la recaudación de impuestos, viabilizar las transferencias de fondos y asegurar el envío de remesas, fin último del esquema fiscal español en América.

Asimismo, dado que los nuevos gobiernos pos-1810 heredaron las estructuras tributarias coloniales -impuestos, recursos, deudas, etc. - consideramos que buena parte de las dificultades de la construcción fiscal en los estados provinciales durante el siglo XIX hallaron sus raíces en este «legado» colonial. Nos preguntamos entonces acerca de las características que presentaban los fondos regionales en la coyuntura de 1810 ¿recibieron los nuevos gobiernos saldos acumulados en las tesorerías regionales o por el contrario la esca- 
sez de recursos caracterizó a las haciendas provinciales? ¿Cómo era la situación financiera de estas tesorerías a fines de la colonia? ¿Cuál era el peso de la deuda en relación a la capacidad de recaudación tributaria en estas jurisdicciones?

En miras de este núcleo de problemas, en el presente artículo presentamos un examen de la estructura tributaria de la Caja Real de Mendoza, ubicada en la región cuyana del Virreinato del Río de la Plata, entre los años 1779-1810. La misma comprendía las jurisdicciones de la caja principal de Mendoza y de las tesorerías menores de San Juan y San Luis - futuros estados provinciales - (ver mapa). La investigación pretende contribuir a la reconstrucción del mosaico hacendístico que conformaba el Río de la Plata durante los últimos años coloniales. Justipreciar la evolución de las recaudaciones de impuestos, las características del gasto fiscal en la región y, en particular, la capacidad de extracción de recursos que la administración tributaria de la capital ejerció sobre estas jurisdicciones del interior constituyen objetivos caros a nuestra investigación.

En pos de este horizonte reconstruiremos, para el período 1779-1810, la evolución de las recaudaciones y estructura de principales gastos de la caja, la magnitud de los suplementos - subsidios - recibidos, el volumen y composición de los recursos enviados a la capital (y a otras jurisdicciones) así como la capacidad de los oficiales de retener saldos líquidos en la caja. También se analizará la evolución de los diferentes mecanismos de financiamiento y se abordarán en detalle los cambios que la estructura de ingresos exhibió durante el último lustro colonial, en plena crisis del imperio español.

\section{LAS CAJAS DE HACIENDA REGIONALES: UN CONTEXTO HISTORIOGRÁFICO}

El medir la magnitud de las exacciones coloniales constituye a estas alturas un tema clásico de la historiografía fiscal. Enfocadas tradicionalmente sobre las llegadas de oro y plata al continente europeo - públicas y de particulares - las investigaciones sobre este tema son diversas ${ }^{2}$. Estas grandes perspectivas han dado lugar a la aparición de estudios con miradas más acotadas, que persiguen objetivos similares en cuanto a medir el impacto de la extracción de riquezas del imperio español sobre las economías americanas, o el éxito del reformismo borbón en su cruzada por obtener mayores recursos de sus colonias americanas.

2 Sin ánimo de exhaustividad, los estudios clásicos que pueden citarse son Haring (1979) [1939], Morineau (1986) y Hamilton (2000) [1962]. 
Lentamente, entonces, se ha pasado de estudiar las grandes transferencias de caudales recibidas en la metrópoli a escudriñar en cuentas más humildes pertenecientes a administraciones virreinales y a cajas reales de espacios más acotados. En las últimas décadas se han producido avances significativos en esta línea de estudios, principalmente enfocados en caracterizar el funcionamiento del sistema de «situados» coloniales. A través del examen de estas remisiones tanto Marichal como Grafenstein han graficado bien la lógica fiscal de subsidios que, originados en las arcas novohispanas, se destinaban principalmente a gastos militares en el Caribe español ${ }^{3}$. El peso que sobre la economía y finanzas mexicanas tuvo este flujo de caudales perjudicó el desempeño económico de la región, expresado en un drenaje de unos 250 millones de pesos desde las tesorerías novohispanas hacia la Metrópoli, el Caribe y Filipinas durante todo el siglo XVIII. Similar esquema de transacciones se habría registrado entre las regiones correspondientes a la capitanía de Chile, el Perú y Nueva Granada, donde el traspaso de recursos con fines de defensa habría alimentado el crecimiento de puntos neurálgicos del comercio colonial como Cartagena, Concepción, Valdivia, Panamá y Portobelo 4 .

En el caso del Virreinato rioplatense, las transferencias más y mejor examinadas las constituyen las que vinculaban a la región minera de Potosí con Buenos Aires: el llamado situado potosino ${ }^{5}$. Todos los trabajos convergen en otorgarle centralidad al situado en la estructura de ingresos de la Real Hacienda virreinal, que encontraba sus principales erogaciones en los gastos militares/administrativos. También coinciden en la tendencia al crecimiento en el volumen de los envíos desde el Alto Perú a Buenos Aires a lo largo del siglo XVIII, para protagonizar una caída hacia el final del régimen colonial, durante la década de 1800 .

Nuestra investigación se inserta en el campo de trabajos abocados a identificar las características de los recursos que desde las diversas cajas regionales confluyeron hacia las tesorerías generales. La mirada más ambiciosa sobre esta temática la constituyen los estudios de John TePaske y Herbert Klein ${ }^{6}$, quienes a partir de fuentes conocidas como «cartas-cuenta», elaboraron una base de datos de los gastos e ingresos de todas las cajas regionales de las colonias americanas. Especialmente el segundo, a través de diferentes trabajos 2012.

3 Marichal y Rodríguez Venegas, 1999. Marichal, 2010: 173-209. Marichal y Grafenstein,

4 Flores Guzmán, 2012: 33-60. Meisel, 2012: 1-26.

5 Halperín Donghi, 1982. Moutoukias, 1988. Mira y Gil Lázaro, 2003: 37-56. Cuesta, 2009: 27-56. Wasserman, 2016.

6 TePaske y Klein, 1982-1990. 
ha analizado las estructuras de ingresos-egresos de las diferentes jurisdicciones fiscales hispanoamericanas ${ }^{7}$. Para el caso rioplatense, Klein ha indagado en las cuentas para el período 1630-1809, en donde el análisis de las transferencias entre cajas (estudiadas a partir del ramo «otras tesorerías») arrojó como resultado un aumento de los movimientos de fondos entre oficinas de hacienda hacia el final del período colonial, sin dudas alimentado por el incremento de los valores del situado potosino - Alto Perú- destinado a la caja de Buenos Aires.

Lamentablemente, la organización de la información presentada por Klein — en promedios por décadas, para todo el Virreinato - no permite apreciar la composición regional de las transferencias, lo cual imposibilita identificar qué cajas eran emisoras y cuáles receptoras de saldos y en qué proporciones. Obstáculo similar presenta la obra de Halperín Donghi sobre la caja de Buenos Aires, en donde los ingresos desde otras cajas dentro y fuera del Virreinato fueron agrupados en quinquenios sin referencias a sus jurisdicciones de origen $^{8}$.

Alejandra Irigoin y Regina Grafe han analizado las remisiones de caudales entre todas las reales cajas del imperio español en América para los períodos $1785-1789$ y $1796-1800^{9}$. A partir de los datos brindados por TePaske y Klein, las autoras pretenden desglosar de manera más minuciosa los envíos de saldos entre las diferentes tesorerías a fin de caracterizar el funcionamiento del sistema fiscal del imperio español. De modo similar a Klein, afirman que la mayor cantidad de transferencias entre cajas observadas hacia el final del período colonial expresaría una mayor autonomía de los poderes locales respecto del afán centralizador borbónico. Sin embargo, las estimaciones de las autoras en este punto no logran dar cuenta de las omisiones y manipulaciones contables presentes en las cartas-cuentas. Los montos y sentido de las transferencias consignados deben ser tomados con cuidado, pues presentan distorsiones que invalidan, sino sus hipótesis, sí la información sobre las que basan sus reflexiones ${ }^{10}$.

7 Klein, 1998; 1999: 12-30.

8 Halperín Donghi, 1982.

9 Irigoin y Grafe, 2006: 1-63.

10 Por ejemplo, según las autoras, en el año 1799 desde la caja principal del Virreinato se enviaron 51.000 \$ hacia la caja de Paraguay. Sin embargo, en el libro manual de la tesorería de Buenos Aires consta que la suma enviada era un reintegro. Es decir que ese dinero —originado en el ramo de «donativos voluntarios»— había sido recaudado en la región guaraní y girado a la capital para suplir otros gastos, para luego ser repuesto. El sentido de la circulación de fondos presenta así una lógica inversa a la planteada por las autoras, que suponen, erróneamente, un subsidio de la tesorería general a la caja de Asunción. Ver Libro 
El principal obstáculo que presentan los trabajos basados en los resúmenes de cuenta se vincula a cuestiones metodológicas en la interpretación de la información que contienen. Al ser un sumario del ejercicio contable anual, estas fuentes ocultan operaciones financieras que dificultan estimar con precisión las cifras de transferencias entre tesorerías. Los ramos de hacienda se dividían en tres categorías: los de real hacienda, de los cuales se disponía libremente, los «particulares» que tenían un fin específico, y los «ajenos», que la real hacienda recaudaba, pero en teoría no le pertenecían ${ }^{11}$. Como describe y analiza Amaral, las llamadas «transferencias financieras», consistían en traspasos de dinero de un ramo a otro, con el fin de destinar fondos a gastos específicos. En general, las transferencias se realizaban desde los ramos particulares y ajenos hacia los de Real Hacienda, a fin de solventar gastos corrientes. Como las devoluciones de estos fondos podían extenderse en los años posteriores, los valores recaudados se «inflaban» con los reintegros. Lo mismo ocurría con los gastos o «data», incrementados por las salidas de dinero ${ }^{12}$. Por otra parte, la inclusión de las denominadas «existencias» en cada ramo también generaba distorsiones, dado que dentro de la recaudación anual se contaba también el saldo o residuo del año anterior. Ambas prácticas tuvieron como resultado el distorsionar —en general aumentar - el monto de las recaudaciones y transferencias consignadas en las cartas-cuentas.

Pese a estas dificultades, los estudios basados en estas fuentes pueden servirnos para contextualizar a la caja real de Mendoza dentro del heterogéneo panorama tributario del Río de la Plata. Si seguimos las estimaciones de Irigoin y Grafe, la caja cuyana se ubicaría dentro de la red de transferencias del Río

Manual caja de Buenos Aires, Archivo General de la Nación, Buenos Aires (AGN), Sala XIII 44-3-12.

11 Carlos Contreras distingue al respecto para el caso peruano: «La Real Hacienda en el Perú partía de la clasificación de su recaudación en tres grandes ramos; a saber: Real Hacienda o Ramos Propios, Ramos Particulares y Ramos Ajenos. El primero comprendía las contribuciones que los administradores estatales recogían o centralizaban y sus montos pasaban a formar una masa o tesoro común, con el que se afrontaban los gastos del virreinato. El segundo estaba compuesto de contribuciones que, aunque pertenecían también a la Real Hacienda, tenían destinos predeterminados, por lo que no entraban, al menos en teoría, a la masa común del tesoro. Las partidas de Ramos Ajenos no pertenecían, en cambio, a la Real Hacienda del virreinato, aunque por razones de comodidad, tradición o economía de recursos, ésta se encargaba de su cobranza. Ella simplemente debía transferir los fondos a quienes les correspondía: instituciones o corporaciones internas, como la iglesia, los militares en retiro, o las comunidades de indios, o externas, como la Iglesia de Roma o la Universidad de Salamanca», Conteras, 2002: 125. Agradezco a los evaluadores anónimos la referencia a esta obra.

12 Amaral, 2014: 387 y ss. 
de la Plata ${ }^{13}$ como una caja emisora de fondos durante los dos períodos analizados (1785-1789 y 1796-1800). Dentro del grupo de cajas rioplatenses que fueron netamente emisoras de remesas, Mendoza se habría ubicado en el tercer lugar, alcanzando envíos por 8.716 \$, sólo detrás de Santa Fe 19.546 (\$) y Córdoba (14.473\$). En cambio, si comparamos las cajas por volúmenes de fondos transferidos (ya fuera enviados o recibidos), las tesorerías más importantes eran sin duda Buenos Aires (con fuerte superávit gracias al situado potosino), Montevideo, Paraguay, Salta, Córdoba y Santa Fe, para luego ubicarse Mendoza ${ }^{14}$. Lejos entonces de ser una tesorería menor, la caja mendocina se emplazaba en un territorio caracterizado por la presencia de producción agraria y minera significativa, así como atravesado por circuitos comerciales que vinculaban el litoral rioplatense con las economías regionales de Chile, aspectos todos que le otorgaban una potencialidad recaudatoria relevante.

Cabe señalar que la cuestión metodológica sobre las fuentes utilizadas generó un intenso debate entre Herbert Klein y Samuel Amaral sobre el imperativo de combinar el estudio de las cartas-cuenta con los libros mayores y manuales de caja para delimitar el influjo de las maniobras contables sobre los números reales de la recaudación y los fondos transferidos ${ }^{15}$. Aspecto sobre el cual también llamó la atención Marichal al señalar la necesidad de recurrir a investigaciones que aborden la escala regional para arribar a conclusiones más firmes acerca de las transferencias de fondos al interior de los virreinatos americanos ${ }^{16}$. Sin embargo, es muy poco lo que se ha avanzado en este sentido a partir del estudio de espacios regionales más acotados y con documentación primaria que permita caracterizar fielmente la magnitud de recursos que las tesorerías generales lograron atraer hacia sus arcas. Para el caso del Virreinato rioplatense se destacan algunas pocas investigaciones que han abordado, con perfil disímil, esta problemática.

13 Las autoras ubican a la tesorería cuyana erróneamente dentro de la red de transferencias hacia Santiago de Chile. Si bien como veremos más adelante, la caja mantuvo lazos con la tesorería trasandina, especialmente a través de los ramos eclesiásticos. Desde su creación en 1778 la caja de Mendoza quedó bajo la jurisdicción de Buenos Aires, adonde enviaba sus cuentas.

${ }^{14}$ Luego se ubicaban las tesorerías menores de Jujuy, Santiago del Estero, Catamarca, Corrientes, La Rioja, San Juan, San Luis, Tucumán y Puno, dependientes de las cajas principales y con volúmenes de recursos mucho menores. Maldonado, si bien recibía fondos importantes para promover el poblamiento de la región, poseía recaudaciones propias limitadas, como detallaremos más adelante.

15 Klein, 1984: 310-312. Amaral, 1984: 287-295.

16 Marichal y Rodríguez Venegas, 1999: 79. Hemos señalado la pertinencia de esta línea de investigación en el marco de una posible agenda de problemas en Galarza, 2015. 
La investigación de Wayar sobre la caja de Salta — gobernación del Tucumán - entre 1759 y 1808 deja en evidencia el aumento progresivo en valores nominales de los fondos remitidos hacia la tesorería general del Virreinato ${ }^{17}$. No obstante, las remesas habrían mostrado una caída en relación a los saldos líquidos acumulados en la tesorería salteña, siendo cada vez mayor la recaudación retenida en la administración local. Si bien el caso de la gobernación del Tucumán evidencia cierto éxito en el objetivo de extraer mayores recursos de las colonias, también muestra las dificultades existentes en los intentos de centralización borbónica, expresados en reticentes transferencias de saldos desde las cajas regionales.

La otra cara de la moneda la representa la caja de Maldonado - actual Uruguay- La investigación de Biangardi demuestra que la tesorería poseía humildes recaudaciones propias y en cambio se constituyó en receptora de fondos desde Montevideo y Buenos Aires, puesto que su ubicación geográfica estratégica como región lindante con el imperio portugués incentivó a la Corona a inyectar recursos para incentivar el poblamiento ${ }^{18}$. En tanto, los trabajos sobre Buenos Aires permiten observar su estructura de ingresos-egresos para los últimos años coloniales, pero no identifican ni detallan la calidad y cantidad de fondos recibidos desde las cajas del interior rioplatense ${ }^{19}$. Especialmente Cuesta y Amaral han indagado en la información contenida en los libros mayores, pero con el afán de dilucidar los montos efectivamente recaudados en cada ramo. Con particular énfasis en la cuestión metodológica, el trabajo de Amaral permite evaluar las posibilidades que los libros mayores brindan para apreciar más y mejor el efecto distorsivo de las operaciones financieras en los valores de las recaudaciones de impuestos de las cartas-cuentas.

Salta del Tucumán, Maldonado y Buenos Aires representan sólo una parte del escenario fiscal rioplatense, por lo que es poco lo que se sabe aún acerca de la forma en que cada región constituyente del entramado virreinal aportó al drenaje de recursos que la metrópoli buscó incrementar para afrontar sus urgencias financieras. Lo que sigue a continuación pretende aportar información acerca de cómo la región de Cuyo se insertó en el sistema de transferencias de recursos que la Monarquía española intentó dinamizar hacia

17 Wayar, 2011: 1-29.

18 El autor señala que más del $86 \%$ de los ingresos de la caja correspondían a transferencias desde otras tesorerías, mientras que el siguiente en importancia, el ramo de «estancias», apenas contribuyó con un 4\% (50.000 \$) sobre el total entre 1782 y 1786. Biangardi, 2016: 7-35.

19 Klein, 1773: 369-400. Halperín Donghi, 1982. Cuesta, 2009: 27-56. Amaral, 2014: 381-436. 
fines del período colonial, delimitando una pesquisa que aborde los libros mayores y manuales de la caja mendocina como principal insumo documental.

\section{LOS INGRESOS DE LA CAJA CUYANA}

Ya ha sido señalado que la organización tributaria rioplatense se componía de cajas regionales que enviaban recursos e información a la Real Hacienda situada en la capital. La jurisdicción de la caja de Mendoza, ubicada en la región cuyana, se extendía a la provincia homónima e incluía las tesorerías menores de San Juan y San Luis de la punta (ver mapa) ${ }^{20}$. Estas oficinas enviaron con regularidad sus recursos a la caja mendocina, ingresando las recaudaciones en los ramos correspondientes. Por lo tanto, la información de los libros de la caja de Mendoza incluye en cada ramo los ingresos de las tres jurisdicciones que la componían. Recién en los años finales de la colonia, entre 1803 y 1810, durante algunos años se ingresaron desde San Luis y San Juan los excedentes de la recaudación en el rubro «otras tesorerías» sin especificar el origen de los fondos.

Una primera aproximación al registro de los libros mayores y manuales de la caja cuyana permite discriminar los ingresos que consideramos «genuinos» (fruto del cobro de impuestos) de aquellos vinculados a operaciones contables y transferencias. Los valores consignados en la tabla n..$^{\circ} 1$ nos permiten apreciar los montos de las recaudaciones propias de la caja en cada año, correspondientes a los ramos de Real Hacienda en común, particulares y ajenos - descontando remisiones desde otras tesorerías, suplementos y saldos de años anteriores - comparadas con las erogaciones propias de la administración regional — sin contar las salidas por remesas-

Se presenta un estado de cuentas de la jurisdicción cuyana a partir de la situación hipotética de cómo hubieran resultado los ingresos/egresos a fin de cada período (año) contable en caso de haber constituido una administración autónoma. Este ejercicio sirve para apreciar que en pocos años los gastos propios de la caja superaron a los ingresos genuinos, lo que da cuenta de una hacienda regional que estaba en condiciones de sufragar sus propias erogaciones sin mayores necesidades de recibir suplementos desde la capital.

El año 1784 es el primero en el que las salidas superaron a las entradas, escenario que se repitió entre 1787-1788, 1794, y especialmente entre 18051807 y 1810. Los primeros tres momentos se correspondieron con el aumen-

20 Ver Santos Martínez, 1961. Comadrán Ruiz, 1960: 82-111. 


\section{Mapa 1. Región de Cuyo (Mendoza, San Juan de la Frontera y San Luis de la punta) en Río de la Plata, SEGÚN MAPA DE ARROWSMITH y LEWIS DE 1812}

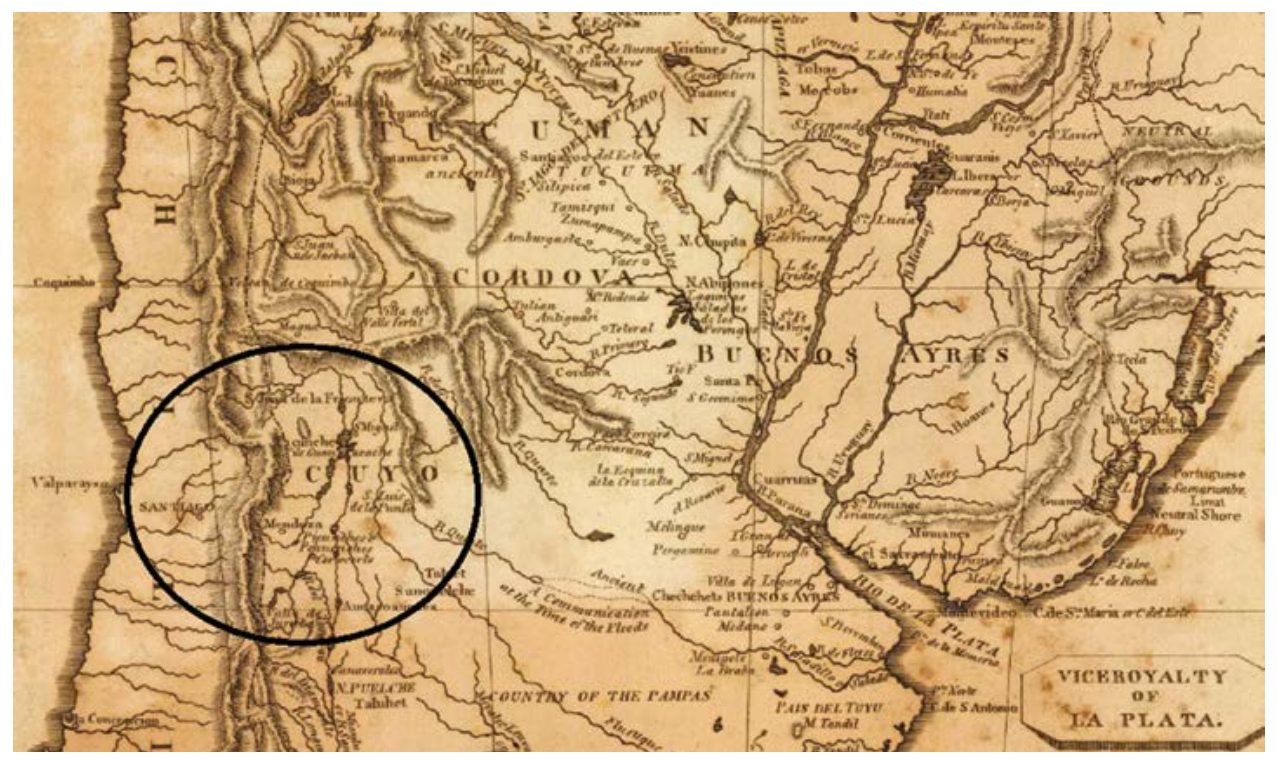

Fuente: David Rumpsey Map Collection. Disponible en http://www.davidrumsey.com.

to de las erogaciones de frontera, en donde el solventar los agasajos de indios, el pago de expediciones punitivas y manutención de tropas en fuertes y destacamentos presionó sobre la estructura tributaria. En cambio, los últimos se identificaron con aumentos de los gastos vinculados a la guerra. Si durante 1805 fue la caída de la recaudación lo que se tradujo en el déficit, durante 1806 y 1807 la militarización reinante en el Río de la Plata elevó las salidas por compra de armamentos y pago a proveedores, por manutención y traslado de prisioneros ingleses y por sobre todo incrementó los pagos a la tropa, que se vieron multiplicados exponencialmente (ver gráfico n. ${ }^{\circ} 1$ ). Durante 1810 el saldo negativo se explica mejor por una especie de derrumbe de los ingresos: la caja no percibió fondos desde San Luis, como habitualmente sucedía, y no se registraron depósitos ni donativos, a la par que disminuyeron los valores recaudados en todos los ramos.

Por último, los datos correspondientes a la última columna de la tabla n. ${ }^{\circ} 1$ exhiben las diferencias entre la suma del ingreso anual y el residuo heredado del año anterior restados los egresos propios de la jurisdicción. Los números muestran una evolución positiva durante todo el período abordado, con ex- 
cepción de tres momentos: 1788, 1790 y 1805-1807. Esto significa que, si la caja cuyana hubiera logrado utilizar todos sus superávits para afrontar sus gastos, los saldos acumulados le hubiesen permitido afrontar sin mayores contratiempos los aumentos de erogaciones durante la mayor parte de los períodos aludidos, salvo la particular coyuntura de 1805-1807. No obstante, esta potencial autonomía tributaria estuvo atravesada por la lógica de recepción de suplementos/envío de remesas que caracterizaba al funcionamiento de la Real Hacienda, de la cual formaba parte la caja cuyana y que influyó en las cuentas de caja, lo que analizaremos más adelante.

Tabla 1. Ingresos y egresos propios, Caja Real de Mendoza 1779-1818

\begin{tabular}{|c|r|r|r|r|r|}
\hline Año & Recaudación & \multicolumn{1}{c|}{ Gastos } & \multicolumn{1}{c|}{ Saldo } & \multicolumn{1}{c|}{ Existencia (anterior) } & (R+E)-G \\
\hline 1.779 & 11.953 & 7.375 & 4.578 & 5.322 & 9.900 \\
\hline 1.780 & 18.378 & 9.203 & 9.175 & 3.799 & 12.974 \\
\hline 1.781 & 18.976 & 10.311 & 8.665 & 9.177 & 17.842 \\
\hline 1.782 & 15.223 & 8.772 & 6.451 & 8.799 & 15.250 \\
\hline 1.783 & 15.035 & 8.054 & 6.981 & 6.797 & 13.778 \\
\hline 1.784 & 14.651 & 19.934 & -5.283 & 7.143 & 1.860 \\
\hline 1.785 & 24.608 & 18.813 & 5.795 & 1.380 & 7.175 \\
\hline 1.786 & 22.781 & 10.664 & 12.117 & 5.363 & 17.480 \\
\hline 1.787 & 16.338 & 25.058 & -8.720 & 10.349 & 1.629 \\
\hline 1.788 & 17.882 & 30.196 & -12.314 & 8.065 & -4.249 \\
\hline 1.789 & 15.105 & 18.365 & -3.260 & 7.167 & 3.907 \\
\hline 1.790 & 15.852 & 18.853 & -3.001 & 2.276 & -725 \\
\hline 1.791 & 15.264 & 12.872 & 2.392 & 2.071 & 4.463 \\
\hline 1.792 & 16.287 & 18.728 & -2.441 & 3.994 & 1.553 \\
\hline 1.793 & 21.592 & 14.756 & 6.836 & 3.215 & 10.051 \\
\hline 1.794 & 19.628 & 22.635 & -3.007 & 10.523 & 7.516 \\
\hline 1.795 & 17.999 & 15.187 & 2.812 & 8.371 & 11.183 \\
\hline 1.796 & 22.530 & 25.732 & -3.202 & 11.357 & 8.155 \\
\hline 1.797 & 12.625 & 14.328 & -1.703 & 6.671 & 8.761 \\
\hline 1.798 & 30.865 & 24.194 & & 15.427 \\
\hline & & & & & \\
\hline
\end{tabular}




\begin{tabular}{|c|r|r|r|r|r|}
\hline \multicolumn{1}{c|}{ Año } & Recaudación & \multicolumn{1}{c|}{ Gastos } & \multicolumn{1}{c|}{ Saldo } & \multicolumn{1}{c|}{ Existencia(anterior) } & (R+E)-G \\
\hline 1.799 & 23.061 & 17.673 & 5.388 & 12.721 & 18.109 \\
\hline 1.800 & 30.265 & 12.834 & 17.431 & 16.785 & 34.216 \\
\hline 1.801 & 30.071 & 16.745 & 13.326 & 32.676 & 46.002 \\
\hline 1.802 & 32.813 & 15.295 & 17.518 & 21.090 & 38.608 \\
\hline 1.803 & 31.633 & 17.759 & 13.874 & 37.399 & 51.273 \\
\hline 1.804 & 41.975 & 19.348 & 22.627 & 8.807 & 31.434 \\
\hline 1.805 & 15.726 & 30.634 & -14.908 & 1.400 & -13.508 \\
\hline 1.806 & 45.032 & 53.015 & -7.983 & 1.593 & -6.390 \\
\hline 1.807 & 25.057 & 69.209 & -44.152 & 4.892 & -39.260 \\
\hline 1.808 & 46.682 & 27.215 & 19.468 & 10.365 & 29.833 \\
\hline 1.809 & 31.214 & 27.931 & 3.283 & 7.593 & 10.876 \\
\hline 1.810 & 21.422 & 26.523 & -5.101 & 7.727 & 2.626 \\
\hline
\end{tabular}

Fuente: elaboración propia en base a Libros mayores y manuales caja de Mendoza, AGN, Sala XIII, 10-09-01 (legajo n. ${ }^{\circ}$ 1: libros manuales 1779, 1780 y 1781, libro común general 1782); 10-09-02 (legajo n. ${ }^{\circ} 2$ : libros manuales 1783 y 1784); 10-09-03 (legajo n. ${ }^{\circ} 3$ : libro principal 1785, libro mayor y libro de caja 1786); 10-09-04 (legajo n. ${ }^{\circ} 4$ : libros mayor y de caja 1787 , libros manual, mayor y de caja 1788); 10-10-01 (legajo n. ${ }^{\circ}$ 5: libros manuales 1789 y 1790); 10-10-02 (legajo n. ${ }^{\circ}$ 6: libros manuales 1791 y 1792); 10-10-03 (legajo n. ${ }^{\circ}$ 7: libros manuales 1793 y 1794); 10-10-04 (legajo n. ${ }^{\circ} 8$ : libros manuales 1795 y 1796); 11-01-01 (legajo n. ${ }^{\circ} 9$ : libros manuales 1797 y 1798); 11-01-02 (legajo n. ${ }^{\circ} 10$ : libros manuales 1799 y 1800); 11-0103 (legajo n. $^{\circ} 11$ : libros manuales 1801 y 1802); 11-01-04 (legajo n. ${ }^{\circ} 12$ : libro mayor y manual 1803); 11-01-05 (legajo n. ${ }^{\circ}$ 13: libro mayor y manual 1804); 11-02-01 (legajo n. ${ }^{\circ}$ 14: libro mayor y manual 1805); 11-02-02 (legajo n. ${ }^{\circ} 15$ : libro mayor y manual 1806); 11-02-03 (legajo n. ${ }^{\circ}$ 16: libro mayor y manual 1807); 11-02-04 (legajo n. ${ }^{\circ} 17$ : libros mayores y manuales 1808 y 1809); 11-02-05 (legajo n. ${ }^{\circ} 18$ : libro mayor y manual 1810).

El incremento del volumen presupuestario se evidencia al observar la tendencia de entradas y salidas, la cual se muestra particularmente inclinada a la suba a medida que avanzó el siglo XIX. Como señalamos, los ingresos de la caja no se agotaban en la recaudación de impuestos propia, sino que también recibió fondos desde otras jurisdicciones. En la siguiente tabla constan los ramos de entradas, incluidos aquellos que correspondían a transferencias recibidas en especie y dinero líquido desde otras tesorerías (como bulas, papel sellado, otras tesorerías, préstamos del Cabildo, cobros al gobierno de Chile, tabacos, naipes y azogues). 


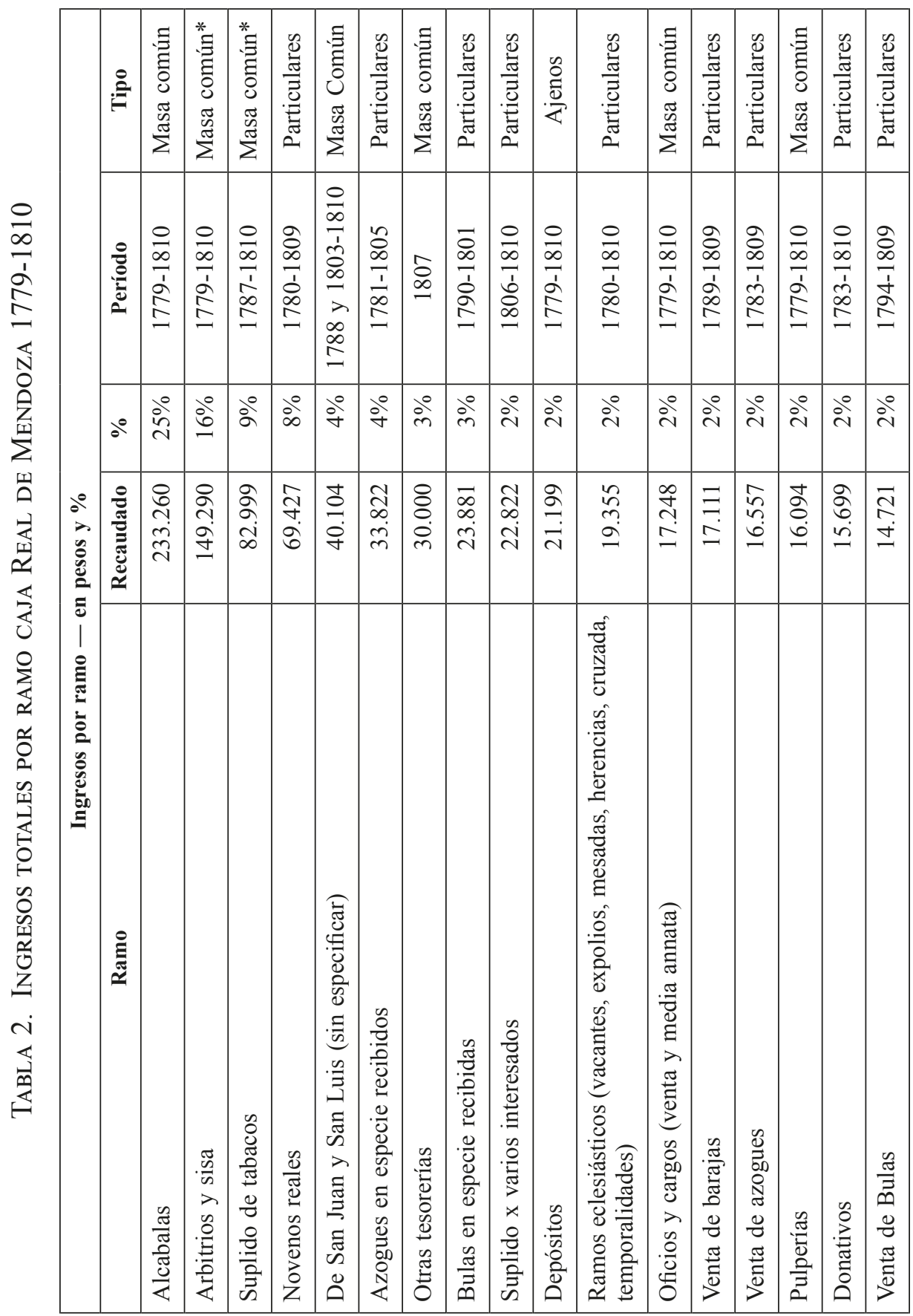




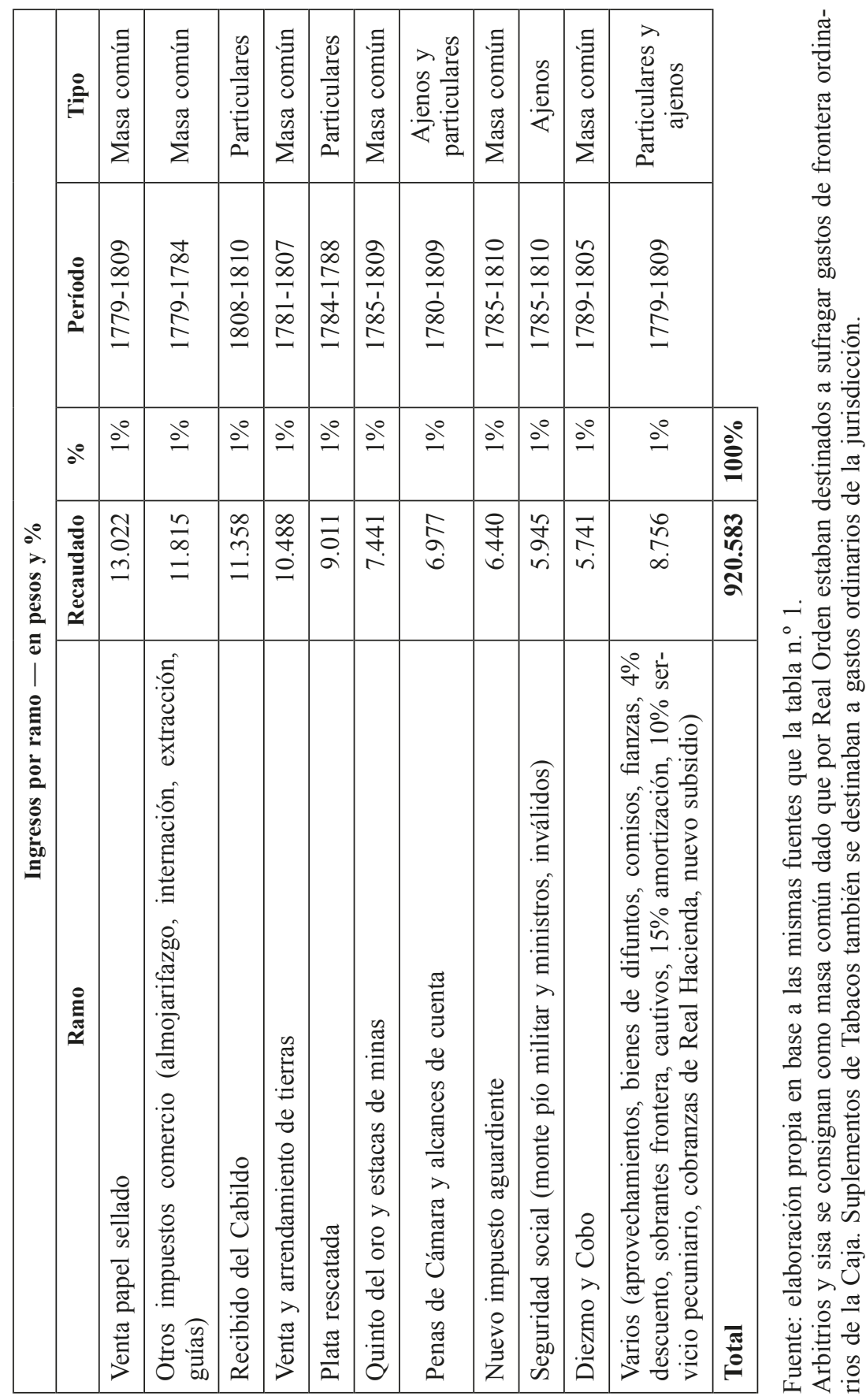


De la información se desprende que las alcabalas y los arbitrios y sisa constituían los impuestos centrales de la caja, tanto por su volumen como por su regularidad — se cobraron todos los años entre 1779 y 1810 - La posibilidad de gravar los circuitos comerciales que atravesaban la región cuyana y la vinculaban con Buenos Aires, Santiago de Chile y Córdoba (entre otros espacios) explica la buena performance recaudatoria de la caja de Mendoza ${ }^{21}$. Además de los famosos «caldos» (vinos) cuyanos, los registros fiscales de Mendoza develan un prolífico tráfico de yerba del Paraguay y otros productos —incluso desde Cádiz - vía Buenos Aires en mulas y carretas hacia Santiago de Chile y Valparaíso ${ }^{22}$.

Por su parte, los ingresos correspondientes a novenos reales muestran la relevancia de la producción agraria y del cobro de diezmos en la jurisdicción, al tiempo que los suplementos del estanco del tabaco —iniciados en 1787constituyeron también uno de los renglones más significativos de la estructura tributaria. Todos estos ramos formaban parte de la llamada «masa común», es decir los ingresos propios de la caja que se utilizaban para solventar sus gastos.

Si se consideran los impuestos por rama de actividad, la relevancia de la inclusión cuyana en los circuitos mercantiles regionales queda graficada en el porcentaje representado por los gravámenes sobre el comercio y la circulación. Las alcabalas, sisa, arbitrios, pulperías, almojarifazgo, extracción, internación, guías e impuesto sobre circulación del aguardiente representaron casi la mitad de lo recaudado en la caja, alcanzando el $45 \%$ sobre el total. Se destacan también los suplementos recibidos, principalmente los estancos reales de tabacos, azogues y barajas, que aportaron cantidades significativas de ingresos (si los contabilizamos junto a los 30.000 \$ recibidos desde Córdoba en 1807 , alcanzan el $20 \%$ ).

Cabe destacar el rubro minería, el cual aportó un nada desdeñable 4\% en base a quintos del oro, ventas de azogue, estacas de minas y rescate de plata, originados tanto en la región mendocina (principalmente Uspallata) como en San Juan y San Luis. Asimismo, los préstamos y donativos representaron un significativo $8 \%$ de los ingresos, con entradas que se incrementaron principalmente entre 1806 y 1810 en razón de empréstitos recibidos de particulares y del Cabildo para solventar los ingentes gastos (ver gráfico n. $\left.{ }^{\circ} 1\right)$.

21 Palomeque, 2006: 255-285. Sovarzo, 2014: 1-28.

22 Ver Aduana de Mendoza 1788-1818, Archivo Nacional de Chile, Santiago de Chile (ANCH), Contaduría Mayor, $1^{\circ}$ Serie. También Libro del Guarda de Cordillera, años 1780 1810, ANCH, Contaduría Mayor, $2^{\circ}$ Serie. 
TABla 3. Ingresos totales POR tiPo - CAJA Real Mendoza 1779-181023

\begin{tabular}{|l|r|r|}
\hline \multicolumn{1}{|c|}{ Tipo impuesto } & Recaudado & \multicolumn{2}{c|}{$\%$} \\
\hline Comercio y circulación & 416.899 & $45 \%$ \\
\hline Suplementos & 157.813 & $17 \%$ \\
\hline Producción agraria & 69.427 & $8 \%$ \\
\hline Préstamos y donativos & 71.078 & $8 \%$ \\
\hline Administración & 49.525 & $5 \%$ \\
\hline Minería & 38.750 & $4 \%$ \\
\hline Ventas & 38.231 & $4 \%$ \\
\hline Transferencias recibidas & 30.000 & $3 \%$ \\
\hline Otros & 48.860 & $5 \%$ \\
\hline Total & $\mathbf{9 2 0 . 5 8 3}$ & $\mathbf{1 0 0} \%$ \\
\hline
\end{tabular}

Fuente: elaboración propia, en base a las mismas fuentes de la tabla n. ${ }^{\circ} 1$.

\section{LOS GASTOS DE LA CAJA CUYANA: FRONTERA Y GUERRA}

¿En qué gastaba todos estos ingresos la caja mendocina? Los datos correspondientes a la estructura de egresos de la administración cuyana fueron agrupados en grandes ítems vinculados a «frontera» (que incluía pagos a guarniciones, expediciones, abastecimiento y —en menor medida- emolumentos a indios amigos) «hacienda y administración» (todo lo concerniente a salarios y \% percibidos por los recaudadores de impuestos) «salarios y gastos militares/guerra» y gastos «ordinarios y extraordinarios» (alquileres, administración de correos, pagos de préstamos y expendios varios). En primer lugar, tal como observamos en el gráfico n. ${ }^{\circ} 1$, a una tendencia al incremento relativamente regular del gasto - con alzas y bajas, pero sin variaciones dramáticas - entre 1779 y 1805, le siguió un fuerte incremento entre 1806-1807, para volver a cánones normales durante los últimos años coloniales.

Entre 1784 y 1785 se registra el primer aumento significativo de las erogaciones — que como vimos generó el primer déficit genuino de la caja-. Si

23 El rubro producción agraria corresponde íntegramente a Reales novenos, en tanto que Ventas incluye tierras (su venta y arrendamiento), bulas y papel sellado. En «otros» se incluyen los ramos menores contenidos en el ítem «varios» del cuadro . $^{\circ} 2$ y los valores correspondientes a San Luis y San Juan, sin especificar. 
en 1784 el crecimiento de las salidas remite a la expedición punitiva contra los indígenas no sometidos de la frontera sur, en 1785 la aparición del renglón «gastos militares», así como los fondos destinados a la recomposición del fuerte de San Carlos en el sur explican el sostenimiento del alto nivel de gastos. En 1787 en cambio, los expendios de frontera (divididos entre raciones a indios amigos y expediciones punitivas) así como los gastos generales (pago a proveedores y abastecedores) dispararon las salidas de la caja, nivel que se mantuvo también durante 1788 al amparo nuevamente de las dispensas fronterizas y un aumento significativo de los salarios militares. Si bien estos últimos retomaron sus niveles anteriores durante los años subsiguientes, la frontera se mantuvo como el principal renglón de salidas hasta bien entrada la década de 1800 .

Gráfico 1. Gastos Caja Mendoza 1779-1810

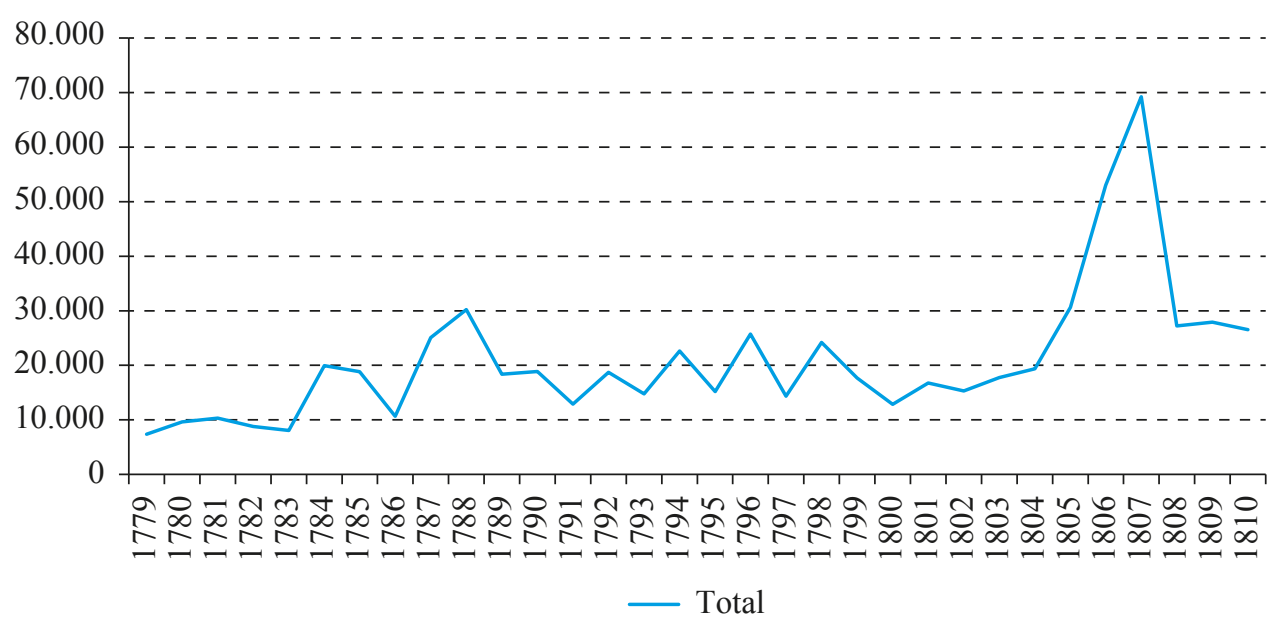

Fuente: elaboración propia en base a las siguientes fuentes consultadas: AGN, Sala XIII 10-0901 (legajo n. ${ }^{0}$ 1, libros manuales 1779, 1780, 1781 y libro común general 1782); 10-09-02 (legajo n. ${ }^{\circ} 2$, libros manuales 1783 y 1784); 10-09-03 (legajo n. ${ }^{\circ} 3$, libro principal 1785 y mayor 1786); 10-09-04 (legajo n. ${ }^{\circ} 4$, libros mayores 1787 y 1788); 10-10-01 (legajo n. ${ }^{\circ}$ 5, libros manuales 1789-1790); 10-10-02 (legajo n. ${ }^{\circ} 6$, libros manuales 1791 y 1792); 10-10-03 (legajo n. ${ }^{\circ}$, libros manuales 1793 y 1794); 10-10-04 (legajo n. ${ }^{\circ} 8$, libros manuales 1795 y 1796); 11-01-01 (legajo n. ${ }^{\circ}$ 9, libros manuales 1797 y 1798); 11-01-02 (legajo n. ${ }^{\circ} 10$, libros manuales 1799 y 1800); 11-01-03 (legajo n. ${ }^{\circ} 11$, libros manuales 1801 y 1802); 11-01-04 (legajo n. ${ }^{\circ} 12$, libro mayor y manual 1803); 11-01-05 (legajo n. ${ }^{\circ} 13$, libro mayor y manual 1804); 11-02-01 (legajo n. ${ }^{\circ} 14$, libro mayor y manual 1805); 11-02-02 (legajo n. ${ }^{\circ} 15$, libro mayor y manual 1806); 1102-03 (legajo n. ${ }^{\circ} 16$, libro mayor y manual 1807); 11-02-04 (legajo n. ${ }^{\circ} 17$, libros mayores y manuales 1808 y 1809); 11-02-05 (legajo n. ${ }^{\circ} 18$, libro mayor y manual 1810). 
La tendencia creciente de las erogaciones iniciada en 1801 se vio profundizada por el protagonismo de los gastos militares a partir de 1805, cuyo dramático aumento generó nuevamente ejercicios deficitarios entre esa fecha y 1807 , así como también en 1810. El rubro militar gravitó con particular peso en la caja mendocina durante el último lustro colonial, aunque la proporción de los diferentes ramos dentro de la masa de erogaciones presentó importantes variaciones a lo largo del período 1779-1810, tal como se aprecia en el gráfico n. ${ }^{\circ} 2$. Allí puede observarse cómo los gastos de frontera representaron la parte del león entre 1779 y 1802 (con un breve interregno durante 1786 y 1787). Luego de esa fecha y hasta 1810 , aunque volvieron a crecer en términos nominales, el marcado ascenso de los expendios militares redujo su participación sobre el total. En cuanto a los ramos castrenses, se consignaron por primera vez en 1785 y se mantuvieron con cierta fuerza hasta 1789 inclusive, para luego representar proporciones menores —en términos absolutos y relativos - hasta 1802 .

Gráfico 2. Gastos (POR AÑo, EN \%)

Caja Real de Mendoza 1779-1810

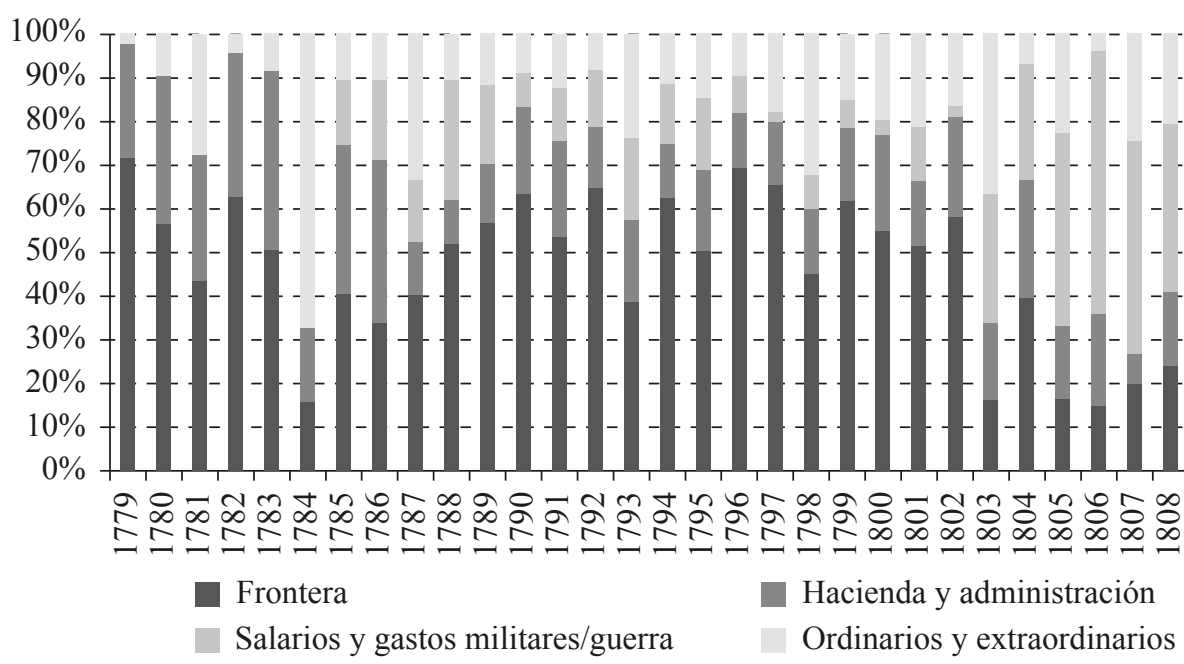

Fuente: elaboración propia, en base a las mismas fuentes que el gráfico n. ${ }^{\circ} 1$.

Mención especial requieren los ramos agrupados en «ordinarios y extraordinarios». Mientras que en 1784 su importancia estuvo dada por la inclusión de los gastos de expedición a la frontera (12.000 \$), el pago a diversos indi- 
viduos en 1787 insufló los números del rubro $(6.365 \$)^{24}$. En 1798 los gastos de flete de elementos como brea y pólvora provenientes de Lima y Santiago de Chile elevaron los gastos ordinarios hasta llegar a los $7.837 \$ 25$, mientras que en 1803 la caja debió hacer frente a emolumentos de párrocos de Ocopa y Chillán, en la región trasandina, llevando el ramo a $6.528 \$^{26}$. En 1805 los casi 7.000 pesos se explican por los pagos concernientes al envío de Alpacas y Vicuñas a España (2.800 \$), que elevaron las erogaciones junto a la compra de caballos $(1.280 \$)^{27}$. Finalmente, en 1808 y 1809, los números se explican por una devolución de préstamos al Cabildo en el primer caso (la mitad de los 5.634 \$) por el pago de salarios atrasados del Resguardo, así como salidas por el ramo de depósitos - pero sin especificar- en el segundo (un total de $9.537 \$)^{28}$. El resto de los años las sumas rondaron cifras comprendidas entre los 1.000 y 3.000 pesos, representando en general entre un 10 y un $20 \%$ del total.

En resumen, puede decirse que durante veinte años la tendencia al crecimiento de los gastos de la caja fue de la mano del protagonismo de los expendios de frontera. A partir de 1803 pero particularmente durante el último quinquenio analizado, el eje de rotación presupuestario se trasladó hacia los gastos militares, principalmente en salarios, pero también en traslados de tropas, abastecimientos de víveres y manutención de prisioneros.

\section{LAS REMESAS Y TRANSFERENCIAS DE FONDOS}

Los rubros señalados no fueron los únicos significativos en cuanto a la salida de recursos de la real caja de Mendoza. El otro aspecto a considerar lo constituye el de las remesas originadas en la jurisdicción. Como señalamos con anterioridad, el sistema fiscal español suponía el envío de los excedentes de cada región hacia la tesorería general, para allí, una vez afrontados los gastos de la administración virreinal, ser exportados en calidad de remesa hacia la península. La administración borbónica, con luces y sombras, intentó mejorar la eficacia de este funcionamiento tributario. Por tanto, considera-

${ }^{24}$ Ver AGN, Sala XIII 10-09-02, legajo n. ${ }^{\circ}$ 2, libro manual 1784, folio n. ${ }^{\circ}$ 60; y Sala XIII 10-09-04, legajo n. ${ }^{\circ} 4$, libro mayor 1787, folios n. ${ }^{\circ} 37$ a 39.

25 AGN, Sala XIII 11-01-01, legajo n. ${ }^{\circ}$ 9, libro manual 1798, folios n. ${ }^{\circ} 110,142$ у 156.

26 AGN, Sala XIII 11-01-04, legajo n. ${ }^{\circ} 12$, libro mayor 1803, folios n. ${ }^{\circ} 11$ y 22.

27 AGN, Sala XIII 11-02-01, legajo n. ${ }^{\circ} 14$, libro mayor 1805, folio n. ${ }^{\circ} 21$.

28 AGN, Sala XIII 11-02-04, legajo n. ${ }^{\circ} 17$, libro mayor 1808 , folio n. ${ }^{\circ} 35$ y libro mayor 1809, folios n. $^{\circ} 19,25$ y 35. 
mos que un examen de las cantidades de dinero que finalmente tomaron rumbo hacia la capital desde la administración mendocina constituye un buen indicador del grado de incidencia (en términos de relativo éxito-fracaso) de las políticas de centralización tributaria al interior del Virreinato.

Hasta aquí, la historiografía sobre el tema ha puesto el acento en la relativa autonomía regional en el manejo de los fondos y las reticencias al envío de remesas, marcando los límites del reformismo borbón en los aspectos fiscales. Sin embargo, como hemos señalado en la introducción, el grueso de los trabajos ha tomado los valores de las cartas-cuentas como piedra fundamental del análisis, con los problemas metodológicos que hemos descrito.

En el gráfico n. ${ }^{\circ} 3$ presentamos una comparación entre los valores de envíos de fondos desde la caja de Mendoza registrados a partir de dos tipos de documentación: por una parte, lo consignado en las cartas-cuentas, las fuentes más utilizadas por la historiografía para analizar estos datos. Por otro, lo que se infiere a partir de los libros mayores y manuales, que muestran una mayor desagregación de los valores y detalle de la información. Como puede observarse, la diferencia entre las series construidas en base a los diferentes documentos es significativa.

Entre 1779 y 1810, los resúmenes de cuenta de la caja real de Mendoza alcanzaron a registrar sólo el $46 \%$ de las salidas de fondos hacia otras jurisdicciones (Un total de 72.815 \$ contra un valor de 168.622 \$ reconstruido a partir de los libros mayores y manuales) reafirmando la necesidad de revisar los libros de caja para reconstruir de manera más fidedigna la estructura de entradas y salidas de las tesorerías regionales.

Consideramos que justipreciar la evolución de las transferencias de fondos en relación a los saldos líquidos existentes en la caja mendocina permite estimar la capacidad de extracción de recursos que la administración de Real Hacienda ejerció sobre la tesorería regional de Mendoza, caracterizando el relativo éxito/fracaso de los intentos centralizadores. Con miras a estos objetivos, resulta útil en primer término comparar las remesas originadas en la caja mendocina con lo ocurrido con su par de Salta (el otro caso rioplatense estudiado a partir de libros mayores y manuales). Entre 1784 y 1808 (la periodización utilizada por Wayar) se giraron en promedio, desde la jurisdicción salteña, unos 3.590 pesos por año, mientras que en Mendoza se enviaron 4.294 pesos anuales. Teniendo en cuenta el total recaudado - genuino - de la caja (ver tabla n. ${ }^{\circ}$ ), las remesas representaron cerca del $20 \%$ del total de la recaudación que ingresaba año a año a la tesorería.

Según muestran los libros mayores y manuales, especialmente entre 17791783, 1798-1804 y 1808-1810 se consignaron las más importantes salidas de recursos. Durante los primeros años, el funcionamiento de la caja recién in- 
Gráfico 3. REMESAS (EN PESOs) CAJA REAL de MENDOZa 1779-1810

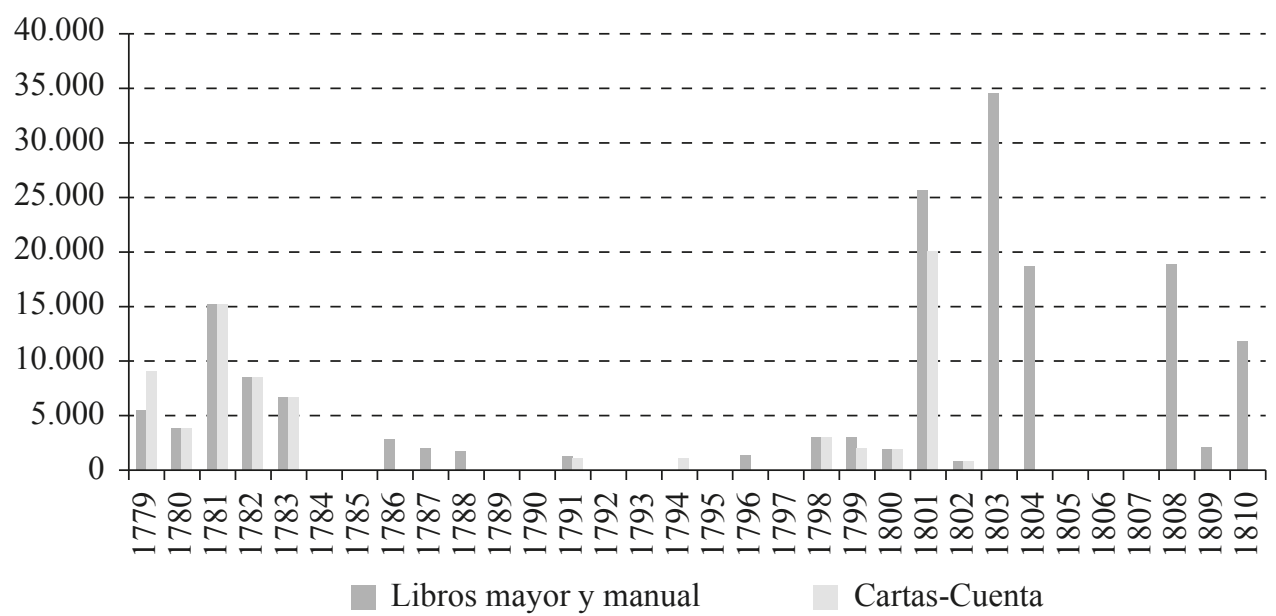

Fuente: elaboración propia en base a TePaske y Klein (1982-1990) y fuentes consultadas. Sólo en 1779 y 1794 las cartas-cuentas marcan mayores salidas que los libros mayores y manuales. En el libro manual de 1779 se aclara que 3.383 \$ se retuvieron en la caja como existencia del año anterior, mientras que en la carta-cuenta se supone que fueron enviados a la capital. Ver AGN, Sala XIII, 10-09-01, Caja de Mendoza 1779-1782 (legajo n. ${ }^{\circ}$ 1, libro manual 1779, folio 79v.). En 1794 las salidas correspondieron 761 \$ a Bulas en especie que se devolvieron a Santiago, mientras que los restantes $320 \$$ se contaron por pago a religiosos que pasaron a Chile; ambas cifras no las consideramos remesas, por eso no se incluyen en el gráfico. Para los demás años ver en AGN, Sala XIII, 10-09-01 (legajo n. ${ }^{\circ}$ 1, libro manual 1780, folio n. ${ }^{\circ} 116$ ); 10-09-01 (legajo n. ${ }^{\circ} 1$, manual 1781, folios ${ }^{\circ}{ }^{\circ} 143-144$; libro común general 1782, folio n. ${ }^{\circ} 68$ ); 10-09-02 (legajo n. ${ }^{\circ} 2$, libro manual 1783, folio $n .{ }^{\circ} 84$ ); 10-09-03 (legajo n. ${ }^{\circ} 3$, libro mayor 1786, folio n. ${ }^{\circ} 15$ ); 10-09-04 (legajo n. ${ }^{\circ} 4$, libro mayor 1787 , folio ${ }^{\circ}{ }^{\circ} 29$ y mayor 1788, folio n. ${ }^{\circ} 46$ ); 10-10-02 (legajo n. ${ }^{\circ} 6$, libro manual 1791, folios n. ${ }^{\circ} 120,124$ y 127); 10 10-04 (legajo n. ${ }^{\circ} 7$, libro manual 1796, folios n. ${ }^{\circ} 132,133$ y 144); 11-01-01 (legajo n. ${ }^{\circ} 9$, libro manual 1798, folio n. ${ }^{\circ} 172$ ); 11-01-02, (legajo n. ${ }^{\circ} 10$, libro manual 1799 , folios 165 a 174 y libro manual 1800 , folios $\mathrm{n} .^{\circ} 172$ y 174); 11-01-03 (legajo n. $^{\circ} 11$, libro manual 1801, folios n. ${ }^{\circ} 179,182$ y 186 y libro manual 1802, folio n. ${ }^{\circ} 175$ ); 11-01-04 (legajo n. ${ }^{\circ} 12$, libro mayor 1803, folios n. $.^{\circ} 11,14,15,20,24,26,27,31,32,33,37$ y 38); 11-01-05 (legajo n. ${ }^{\circ} 13$, libro mayor 1804 , folio $n .^{\circ} 18,21,22,23,25,26,28,30,31$ y 33); 11-02-04 (legajo n. ${ }^{\circ} 17$, libro mayor 1808, folios $n .^{\circ} 16,19,22$ a 28,32 a 35 y libro mayor 1809 , folios $n .^{\circ} 19,34$ y 35); 11-02-05 (legajo n. ${ }^{\circ} 18$, libro mayor 1810 , folios n. ${ }^{\circ} 11,34$ y 35 ).

corporada a la jurisdicción rioplatense pareció aceitado: en 1779 y 1780 los saldos líquidos de la recaudación del año anterior fueron enviados a la tesorería general en Buenos Aires. En 1781, 1782 y 1783 se enviaron los saldos correspondientes a los ramos de Real Hacienda en común, más la totalidad de las ventas de azogue en 1781 (quintales recibidos desde Buenos Aires ese 
mismo año). Esta lógica se vio interrumpida en 1784 cuando los excedentes se destinaron a la ya mencionada expedición a la frontera. En 1786, 1787 y 1788 las salidas (que directamente no constan en las cartas-cuenta) consistieron en plata en pasta, recaudada por la extracción de la misma en la jurisdicción - especialmente en la región de Uspallata-, mientras que los saldos líquidos se conservaron en caja.

El otro momento de importancia de salidas de fondos lo constituyó la coyuntura de cambio de siglo, marcada en buena medida por los conflictos bélicos afrontados por la Corona española y sus urgencias fiscales. Entre 1798 y 1804 se enviaron remesas ininterrumpidamente a la tesorería general, período coincidente con el de mayor volumen de saldos líquidos acumulados a fin de cada ejercicio anual. En 1798 se enviaron 3.000 pesos a la capital por orden del Virrey, mientras que en 1799 las sumas líquidas conducidas a la tesorería llegaron a los 1.205 \$ (excedente de Real Hacienda y venta de bulas). El resto se compuso de traspasos entre cuentas de monte píos e inválidos y 1.239 \$ remitidos a Santiago de Chile por el ramo de expolios. Conformaron un total de 2.958 \$ durante el último año del siglo, que contrastan con los $1.974 \$$ registrados en las cartas-cuentas.

Durante 1800 nuevamente el ramo de expolios con destino a Santiago representó salidas por 1.084 \$, en tanto que a la capital se remitieron 823 \$ del ramo de donativos. En 1801, 1803 y 1804 se registraron las mayores salidas de recursos. Los más de 25.000 \$ que se enviaron a Buenos Aires en 1801 estaban compuestos por excedentes de todos los ramos, incluyendo 5.000 \$ de donativos. En 1802 nuevamente por los ramos eclesiásticos (Vacantes mayores) se condujeron $779 \$$ hacia Chile, constituyendo la única salida de la caja.

En 1803 el funcionamiento del envío de remesas volvió a aceitarse: todo el saldo líquido de 1802 y casi la totalidad de saldos de los ramos de 1803 se enviaron a la tesorería general ${ }^{29}$, constituyendo los $34.462 \$$ el mayor envío de la caja mendocina en todo el período analizado (tal como se aprecia en el gráfico n. ${ }^{\circ} 3$, ninguna de las remesas desde 1803 en adelante constan en las cartas-cuentas). En 1804 una parte (5.900 \$) de los 18.649 \$ de remesas estuvo conformada por transferencias entre cuentas, mientras que el resto (12.750 \$) constituyó dinero líquido compuesto de las existencias de 1803 y los saldos de todos los ramos de 1804 (Real Hacienda común, particulares y ajenos).

29 Sólo se retuvieron 868 \$ de Real Hacienda y 531 \$ de Arbitrios y Sisa para 1804. Ver referencia en fuentes del gráfico n. ${ }^{\circ} 3$. 


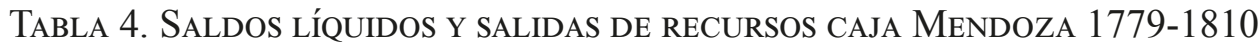

\begin{tabular}{|c|c|c|c|}
\hline Año & Saldos líquidos (enero) & Remesas & Remesas como \% total \\
\hline 1779 & 5.322 & 5.446 & $102 \%$ \\
\hline 1780 & 3.799 & 5.446 & $143 \%$ \\
\hline 1781 & 9.177 & 15.140 & $165 \%$ \\
\hline 1782 & 8.799 & 15.140 & $172 \%$ \\
\hline 1783 & 6.797 & 8.457 & $124 \%$ \\
\hline 1784 & 7.143 & & \\
\hline 1785 & 1.380 & & \\
\hline 1786 & 5.363 & 0 & $0 \%$ \\
\hline 1787 & 10.349 & 2.769 & $27 \%$ \\
\hline 1788 & 8.065 & 1.959 & $24 \%$ \\
\hline 1789 & 7.167 & & \\
\hline 1790 & 2.276 & & \\
\hline 1791 & 2.071 & 0 & $0 \%$ \\
\hline 1792 & 3.994 & & \\
\hline 1793 & 3.215 & & \\
\hline 1794 & 10.523 & & \\
\hline 1795 & 8.371 & & \\
\hline 1796 & 11.357 & 1.213 & $11 \%$ \\
\hline 1797 & 10.464 & & \\
\hline 1798 & 8.756 & 3.000 & $34 \%$ \\
\hline 1799 & 12.721 & 2.958 & $23 \%$ \\
\hline 1800 & 16.785 & 2.958 & $18 \%$ \\
\hline 1801 & 32.676 & 1.907 & $6 \%$ \\
\hline 1802 & 21.090 & 25.628 & $122 \%$ \\
\hline 1803 & 37.399 & 34.462 & $92 \%$ \\
\hline 1804 & 8.807 & 18.649 & $212 \%$ \\
\hline 1805 & 1.400 & & \\
\hline 1806 & 1.593 & & \\
\hline
\end{tabular}




\begin{tabular}{|r|r|r|r|}
\hline Año & Saldos líquidos (enero) & Remesas & Remesas como \% total \\
\hline 1807 & 4.892 & & $160 \%$ \\
\hline 1808 & 10.365 & 16.551 & $27 \%$ \\
\hline 1809 & 7.593 & 2.072 & $153 \%$ \\
\hline 1810 & 7.727 & 11.814 & \\
\hline 1811 & 4.670 & 0 & \\
\hline
\end{tabular}

Fuente: elaboración propia en base a libros mayores y manuales. Los valores que superan el $100 \%$ indican que se envió la totalidad del «residuo» del año anterior junto a parte de la recaudación del año en curso. Las referencias de las remesas en gráfico n.$^{\circ} 3$. Para los saldos líquidos ver: AGN, Sala XIII 10-09-01 (legajo n. ${ }^{\circ} 1$, libro manual 1779, folio n. $^{\circ} 1$; manual 1780, folio n. ${ }^{\circ}$; manual 1781, folio n..$^{\circ} 3$; libro común general 1782, folio n. ${ }^{\circ} 3$ ); 10-09-02 (legajo n. ${ }^{\circ} 2$, libro manual 1783, folio n. $^{\circ} 3$ y manual 1784 , folio n. ${ }^{\circ} 3$ ); 10-09-03 (legajo n. ${ }^{\circ} 3$, libro principal 1785, folio n. ${ }^{\circ} 1$ y manual 1786, folio n. ${ }^{\circ} 2$ ); 10-09-04 (legajo n. ${ }^{\circ} 4$, libro mayor 1787 , folio n. ${ }^{\circ} 2$ y mayor 1788 , folio $n .^{\circ}$ ); $10-10-01$ (legajo n. ${ }^{\circ} 5$, libro manual 1789 , folio.$^{\circ} 3$ y manual 1790, folio n. ${ }^{\circ}$ 3); 10-10-02 (legajo ${ }^{\circ}{ }^{\circ}$ 6, libro manual 1791, folio n. ${ }^{\circ} 3$ y manual 1792, folio n. ${ }^{\circ}$ ); 10-10-03 (legajo n. ${ }^{\circ}$, libro manual 1793, folio n. ${ }^{\circ} 3$ y manual 1794 , folio n. ${ }^{\circ} 3$ ); 10-1004 (legajo.$^{\circ}{ }^{\circ}$, libro manual 1795, folio n. ${ }^{\circ} 3$ y manual 1796, folio $n .^{\circ} 2$ ); 11-01-01 (legajo n. ${ }^{\circ}$, libro manual 1797, folio n. $^{\circ} 3$ y manual 1798, folio $n .^{\circ} 4$ ); 11-01-02 (legajo . $^{\circ} 10$, libro manual 1799, folio n. $^{\circ} 4$ y manual 1800 , folio n. ${ }^{\circ} 4$ ); 11-01-03 (legajo n. ${ }^{\circ} 11$, libro manual 1801, folio n. $^{\circ} 4$ y manual 1802, folio n. $^{\circ} 4$ ); 11-01-04 (legajo n. ${ }^{\circ} 12$, libro manual 1803, folio n. ${ }^{\circ} 1$ ); 11-01-05 (legajo n. ${ }^{\circ} 13$, libro manual 1804, folio n. ${ }^{\circ}$ 1); 11-02-01 (legajo n. ${ }^{\circ} 14$, libro mayor 1805, folio n. ${ }^{\circ} 41$ ); 11-02-02 (legajo . $^{\circ} 15$, libro manual 1806, folio n. ${ }^{\circ} 1$ ); 11-02-03 (legajo n. ${ }^{\circ} 16$, libro manual 1807, folio n. ${ }^{\circ} 1$ ); 11-02-04 (legajo n. ${ }^{\circ} 17$, libro manual 1808 , folio n. ${ }^{\circ} 1$ y manual 1809, folio n. ${ }^{\circ} 1$ ); 11-02-05 (legajo n. ${ }^{\circ} 18$, libro manual 1810, folio n. ${ }^{\circ} 1$ ).

Luego de las voluminosas transferencias de los años 1803-1804, recién en 1808 la caja volvió a generar remesas. Tanto en 1808 como en 1810 los valores enviados se dividieron aproximadamente en un 50 y 50 entre dinero líquido transportado y transferencias entre cuentas. En el primer caso, todos los fondos se dirigieron a la capital virreinal (entre los que se cuentan unos 2000 \$ líquidos destinados a consolidación de Vales Reales). En tanto en 1810 las remisiones de saldos (todas realizadas antes de mayo) se dividieron entre Buenos Aires (5.012 \$ de transferencias entre cuentas) y Córdoba, adonde se enviaron 6.219 \$ líquidos por el ramo de donativos y 574 \$ por cuenta de reales novenos (entre cuentas). En 1809 los escasos envíos sólo se efectuaron mediante operaciones contables con la caja porteña $(1.733 \$$ de los ramos de donativos y depósitos) y con la jurisdicción de Santiago de Chile (358 \$ de expolios). De nuevo, todas estas transferencias de recursos entre 1807 y 1810 no han sido registradas en las cartas-cuentas. 
En la tabla n. ${ }^{\circ} 5$ se presentan las salidas de fondos agrupadas por períodos. Se observa que un $67 \%$ de las remesas giradas a la tesorería general correspondieron al sub-período 1801-1810 — si elegimos una división por décadas, cuando el volumen del situado potosino comenzó a decaer-, o un 72\% si consideramos el lapso 1796-1810, tomando como periodización las guerras europeas que exigieron elocuentes esfuerzos a la hacienda española.

Tabla 5. Remesas según Período. Caja Mendoza 1779-1810

\begin{tabular}{|l|r|r|}
\hline \multicolumn{1}{|c|}{ Período } & \multicolumn{1}{c|}{$\$$} & \multicolumn{1}{c|}{$\%$} \\
\hline $1779-1789$ & 45.880 & $27 \%$ \\
\hline $1790-1800$ & 10.458 & $6 \%$ \\
\hline $1801-1810$ & 112.284 & $67 \%$ \\
\hline Total & $\mathbf{1 6 8 . 6 2 2}$ & $\mathbf{1 0 0 \%}$ \\
\hline $1779-1795$ & 47.161 & $28 \%$ \\
\hline $1796-1810$ & 121.461 & $72 \%$ \\
\hline Total & $\mathbf{1 6 8 . 6 2 2}$ & $\mathbf{1 0 0 \%}$ \\
\hline
\end{tabular}

Fuente: elaboración propia en base a las mismas fuentes del gráfico n. ${ }^{\circ} 3$.

Durante 1803 y 1804, los saldos acumulados —que llegaron a un máximo de 37.400 pesos a fines de 1802 - fueron girados a la tesorería general. La recuperación de las cuentas se operó recién con una inyección de $30.000 \$$ provenientes de Córdoba durante 1807 para gastos de «Real Servicio», lo que permitió el aumento de los saldos líquidos a fines de ese año. Pero nuevamente la salida de fondos durante 1808,1809 y 1810 con destino a la capital — pero también a Córdoba- consumió los recursos disponibles de la caja - reintegrando los $30.000 \$$ recibidos-. El último ejercicio contable colonial arrojó un total de 20.258 \$, de los cuales sólo 4.670 \$ correspondieron a líquido disponible en plata sencilla, mientras que el resto correspondió a especies (azogues, bulas y papel sellado). Este total contenía, además, $2.054 \$$ que aportó a fines de 1810 el ramo de Temporalidades, puesto por el gobierno autónomo de la Primera Junta bajo órbita de la Real Hacienda de Mendoza el 11 de diciembre de ese mismo año, con el objeto de suplir las urgencias presupuestarias. La plata contante y sonante en caja mostró así una tendencia decreciente durante el último quinquenio colonial, sólo disimulada por la inyección de fondos desde Córdoba. Si extendemos la mirada 
hasta 1811, comprobamos que la salida de fondos durante la colonia, así como la baja recaudación de 1810 dejaron como saldo tan solo 147 \$ en plata sencilla en los diferentes ramos y 899 \$ en plata en plancha, el líquido más bajo desde $1779^{30}$.

En síntesis, si bien los fondos remisibles existentes en la caja de Mendoza muestran que los oficiales reales gozaron de márgenes de maniobra para el envío de remesas, puede afirmarse que para 1810 el sistema de transferencias había logrado drenar casi la totalidad de los recursos acumulados en la tesorería regional. Si observamos los años de mayor volumen de giro de recursos, parecen coincidir con los momentos más álgidos de las urgencias fiscales de la Monarquía, cuando debió hacer frente a sendas guerras contra Gran Bretaña (1796-1802 y 1805-1807) y contra Francia (1808-1814) y cuando el monto del situado potosino enviado a la capital rioplatense mermó notablemente en relación a los años anteriores (1801-1810).

\section{LOS SUPLEMENTOS Y EL EQUILIBRIO DE LAS CUENTAS}

Hasta aquí hemos observado cómo los fondos recaudados en la jurisdicción mendocina alcanzaban para solventar sus propios gastos, y cómo los saldos acumulados en las arcas regionales fueron finalmente enviados hacia la tesorería general durante los últimos años de la colonia. No obstante, tanto la salida de fondos, así como algunas necesidades extraordinarias de la caja, especialmente las de guerra y frontera, fueron contrapesadas con la llegada de «suplementos»: ingresos provenientes desde otras tesorerías de la estructura tributaria colonial - como los estancos reales, $\mathrm{u}$ otras haciendas regionales-.

Uno de los aspectos que atendieron las reformas borbónicas fue la implementación y revitalización de los estancos. La lógica de gestión de estos monopolios reales estuvo marcada por el objetivo tributario de la autosuficiencia de las cajas regionales. En realidad, la política borbónica en el Río de la Plata persiguió el horizonte de que los costos de manutención de la frontera del imperio fueran afrontados con insumos de la masa común, a los que se sumaron luego los fondos del tabaco y naipes ${ }^{31}$. Esto se confirma si tenemos en cuenta, además, que la recaudación de propios y arbitrios en Mendoza — en realidad potestad de los Cabildos - quedó en manos de los oficiales

\footnotetext{
30 Ver AGN, Sala XIII 11-02-05, legajo n. ${ }^{\circ}$ 18, libro mayor 1811, folio 45.

31 Por ejemplo, en la caja de Santa Fe encontramos una lógica similar, en donde el estanco del tabaco fue utilizado como insumo para los gastos corrientes - entre ellos los de frontera-. Ver AGN, Sala XIII 9-4-7 (Caja de Santa Fe 1796-1798).
} 
reales de la caja con el precepto de ser destinados a solventar los gastos de la frontera de San Carlos, en el sur provincial.

Los suplementos tuvieron un peso significativo en la estructura de ingresos de la caja cuyana, representados principalmente por los ramos de «azogue» (utilizado para la extracción de plata en la región) y tabaco, que protagonizaron las principales inyecciones de fondos que, como se refleja en la tabla $n .^{\circ} 6$, recibió la administración cuyana. El tercer lugar aparece ocupado por el envío de fondos desde la tesorería de Córdoba en 1807 -único en todo el períodocon destino de cubrir «gastos del Real servicio», incrementados por los costos de guerra. De estos suplementos, siguieron en orden de importancia el suministro de «bulas», la «venta de barajas»y los préstamos «recibidos del Cabildo».

Tabla 6. Suplementos Recibidos. Caja de Mendoza 1779-1810

\begin{tabular}{|c|c|c|c|c|c|c|c|}
\hline & Tabacos & Barajas & Otras tesorerías & Bulas & Azogues & Cabildo & Total \\
\hline 1779 & & & & & & & - \\
\hline 1780 & & & & & & & - \\
\hline 1781 & & & & & 6.092 & & 6.092 \\
\hline 1782 & & & & & & & - \\
\hline 1783 & & & & & & & - \\
\hline 1784 & & & & & & & - \\
\hline 1785 & & & & & & & - \\
\hline 1786 & & & & & 5.867 & & 5.867 \\
\hline 1787 & 8.841 & & & & & & 8.841 \\
\hline 1788 & 15.279 & & & & & & 15.279 \\
\hline 1789 & & 781 & & & & & 781 \\
\hline 1790 & 4.066 & 585 & & 2.645 & & & 7.296 \\
\hline 1791 & 589 & 590 & & & 14.563 & & 15.742 \\
\hline 1792 & & 758 & & & & & 758 \\
\hline 1793 & 471 & 911 & & & & & 1.382 \\
\hline 1794 & 825 & 353 & & & & & 1.178 \\
\hline 1795 & 178 & 683 & & 4.450 & & & 5.311 \\
\hline 1796 & 2.408 & 774 & & & & & 3.182 \\
\hline 1797 & & 696 & & & & & 696 \\
\hline
\end{tabular}




\begin{tabular}{|c|c|c|c|c|c|c|c|}
\hline & Tabacos & Barajas & Otras tesorerías & Bulas & Azogues & Cabildo & Total \\
\hline 1798 & & 1.642 & & & & & 1.642 \\
\hline 1799 & & 1.387 & & 7.557 & & & 8.944 \\
\hline 1800 & & 52 & & & & & 52 \\
\hline 1801 & 1.525 & & & & & & 1.525 \\
\hline 1802 & & 654 & & 1.918 & & & 2.572 \\
\hline 1803 & 397 & 1.143 & & & & & 1.540 \\
\hline 1804 & 2.040 & 1.029 & & 2.160 & & & 5.229 \\
\hline 1805 & 12.964 & 856 & & & 7.300 & & 21.120 \\
\hline 1806 & 6.601 & 669 & & 5.151 & & & 12.421 \\
\hline 1807 & 15.264 & 534 & 30.000 & & & & 45.798 \\
\hline 1808 & 2.748 & 1.100 & & & & 5.423 & 9.271 \\
\hline 1809 & & 1.914 & & & & 914 & 2.828 \\
\hline 1810 & 8.803 & & & & & 5.021 & 13.824 \\
\hline Total & 82.999 & 17.111 & 30.000 & 23.881 & 33.822 & 11.358 & 199.171 \\
\hline$\%$ & $42 \%$ & $9 \%$ & $15 \%$ & $12 \%$ & $17 \%$ & $6 \%$ & $100 \%$ \\
\hline
\end{tabular}

Fuente: elaboración propia en base a fuentes consultadas. Los aportes del estanco del tabaco y naipes, en AGN, Sala XIII, 10-09-04 (legajo n. ${ }^{\circ}$ 4, libro mayor 1787, folio 28; libro mayor 1788, folio 44); 10-10-01, (legajo n. ${ }^{\circ} 5$, libro manual 1789 , folio 70 y manual 1790 , folios 44 , 85); 10-10-02 (legajo n. ${ }^{\circ} 6$, libro manual 1791, folios 44, 84 y manual 1792, folio 84 ); 10-1003 (legajo n. ${ }^{\circ} 7$, libro manual 1793, folios 43, 84 y manual 1794, folios 43, 84; 10-10-04 (legajo n. ${ }^{\circ} 8$, libro manual 1795 , folios 43,84 y manual 1796, folios 43,84 ); 11-01-01, (legajo n. $^{\circ} 9$, libro manual 1797, folio 80 y manual 1798, folio 70); 11-01-02 (legajo n. ${ }^{\circ} 10$, libro manual 1799, folio 78 y manual 1800 , folio 78 ); 11-01-03 (legajo n. $^{\circ} 11$, libro manual 1801, folio 50 y manual 1802, folio 78); 11-01-04 (legajo $\mathrm{n}^{\circ}{ }^{\circ} 12$, libro mayor 1803 , folios 9 y 31 ); 11-01-05 (legajo n. ${ }^{\circ} 13$, libro mayor 1804, folios 18, 30); 11-02-01 (legajo n. ${ }^{\circ} 14$, libro mayor 1805 , folios 19,31 ); 11-02-02 (legajo n. ${ }^{\circ} 15$, libro mayor 1806 , folios $12,19,31$ ); 11-02-03 (legajo n. ${ }^{\circ} 16$, libro mayor 1807, folios 19,31 ); 11-02-04 (legajo n. ${ }^{\circ} 17$, libro mayor 1808 , folios 12, 32 y mayor 1809, folio 32); 11-02-05 (legajo n. ${ }^{\circ} 18$, libro mayor 1810, folios 9, 12, 19, 32). El envío de 30.000 \$ desde Córdoba (Otras tesorerías) en AGN, Sala XIII 11-02-03 (legajo n. ${ }^{\circ} 16$, libro mayor 1807 , folio n. ${ }^{\circ} 17$ ). Los suplementos de azogues y bulas recibidos, en AGN, Sala XIII, 10-09-01 (legajo n. ${ }^{\circ}$ 1, libro mayor 1781, folio 94); 10-09-03 (legajo n. ${ }^{\circ} 3$, libro mayor 1786, folio 25); 10-10-01 (legajo n. ${ }^{\circ} 5$, libro manual 1790, folio 55); 10-10-02 (legajo n. ${ }^{\circ}$ 6, libro manual 1791, folio 56); 10-10-04 (legajo n. ${ }^{\circ} 8$, libro manual 1795, folio 56); 11-01-02 (legajo n. ${ }^{\circ} 10$, libro manual 1799, folio 69); 11-01-03 (legajo n. ${ }^{\circ} 11$, libro manual 1802, folio 69); 11-01-05 (legajo n. ${ }^{\circ}$ 13, libro mayor 1804, folio 18); 11-02-01 (legajo n. ${ }^{\circ} 14$, libro mayor 1805 , folio 36); 11-02-02 (legajo n. ${ }^{\circ} 15$, libro mayor 1806, folios 37 y 38). Aportes del Cabildo en AGN, Sala XIII, 11-02-04 (legajo n. ${ }^{\circ}$ 17, libro mayor 1808, folios 12, 35 y mayor 1809 , folio 35 ) y 11-02-05 (legajo n. ${ }^{\circ} 18$, libro mayor 1810 , folio 34 ). 
En la tabla n. ${ }^{\circ}$ 6, además, se periodizan las llegadas de estos suplementos a la caja cuyana, en donde se evidencia que la primera recepción de fondos desde el estanco de tabacos tuvo lugar en 1787 y 1788, es decir, momento del segundo déficit propio de la caja. ¿Y por qué no ocurrió esto en 1784, primer año deficitario? Consideramos que al ser incluida la expedición punitiva a la frontera realizada ese año dentro de los «gastos extraordinarios», la solución de la administración tributaria resultó en la pausa en el envío de remesas durante 1784-1785, permitiendo la recuperación de los saldos líquidos y retorno de las remisiones de fondos que tuvo lugar en 1786 (los primeros ascendieron a $10.349 \$$, ver tabla $\mathrm{n}^{\circ}$ 4).

En 1787 y 1788 en cambio, los gastos de frontera que presionaron el ejercicio tributario fueron considerados corrientes, ya que principalmente se destinaron al pago de tropa miliciana dedicada al auxilio de indios amigos, al pago de raciones de estos últimos y al mantenimiento del fuerte de San Carlos en la frontera sur. Por lo tanto, la llegada de fondos «extra» desde tabacos coincidió con el primer déficit genuino de la caja, resultado del aumento de erogaciones corrientes de frontera, a diferencia de 1784 cuando resultó de actividades consideradas extraordinarias. En 1789 se sumaron también los fondos por venta de barajas — también estanco real- que alimentaron las cuentas con cifras más modestas pero regulares. La otra coyuntura significativa de recepción de suplementos la constituyó el trienio 1805-1807. Si durante 1805 la caída de las recaudaciones fue afrontada gracias a los más de 12.000 pesos suplidos desde tabacos, durante 1806 y 1807 fueron los gastos de guerra los que marcaron la necesidad de llegada de líquido extra, no sólo desde tabacos sino el ya mencionado envío desde Córdoba.

Diferente fue lo sucedido con el estanco del azogue y bulas. El primero consistió en envíos desde la capital de un insumo central para el beneficio minero, comenzando en 1781. La caja obtenía así fondos por la venta de azogue a los productores, mientras que luego obtenía plata en especie gracias al cobro de impuestos a la producción argentífera. Ambos ingresos eran considerados «particulares», en teoría remisibles a la tesorería de la capital, y sumaron cerca del $4 \%$ del total de fondos percibidos por la administración cuyana. Hacia el final del período, mientras que el ingreso de azogues en especie había sumado un total de 33.822 \$, la venta de los mismos alcanzó los 16.557 \$, explicándose la diferencia por variaciones en la cotización del quintal y saldos existentes en especie a fines de 1810, tanto en Mendoza como en las tesorerías menores de San Juan y San Luis. Algo similar ocurrió con el ramo de Bulas, las cuales entre 1790 y 1796 fueron recibidas desde el arzobispado de Santiago de Chile y sus sobrantes fueron reenviados hacia allí. A partir de esa última fecha, las especies fueron recibidas desde la tesorería 
de Córdoba, y allí remitidos los sobrantes. Al final del período observamos que en la caja se ingresaron un total de 23.881 \$ en diferentes tipos de Bulas (Cuadragesimales, de Santa Cruzada) vendiéndose 14.721 \$ entre 1792 y 1809. La diferencia entre ambas se compone del saldo en especie en 1810 en la caja de Mendoza (8.488 \$) y de lo existente en las tesorerías de la jurisdicción.

Párrafo aparte merecen los ingresos correspondientes a «recibido del Cabildo». Este suplemento se concentró íntegramente en los últimos tres años del período colonial (1808-1810). En 1808 se recibieron del Cabildo 5.423 \$ y en 1809, 914 \$. Ambas cifras introducidas en el ramo de «depósitos». En cambio, en 1810 el Ayuntamiento mendocino aportó 5.021 \$ en el ramo de «donativos», que fueron directamente transferidos a la capital. El total de fondos aportado por la alcaldía mendocina alcanzó entonces un total de 11.349 \$. De este monto, sólo durante el primer año (1808) se devolvieron sumas, apenas 2.663 \$, por lo que la Real Hacienda cuyana comenzó el período independiente con deudas con el cuerpo capitular de Mendoza por valor de unos $3.865 \$$.

Estos empréstitos - con compromiso de devolución que se cumplió escasamente - pueden analizarse de manera conjunta con los «donativos» y préstamos de «varios interesados». Mientras que las donaciones de particulares se concentraron durante la guerra con Gran Bretaña, especialmente entre 1799 y 1801, y también durante los años finales de crisis de la Monarquía (18081810) los préstamos aportados por diversos individuos a tasas diversas (en general, al 6\% anual) concentraron su aporte a la estructura de ingresos de la caja entre 1806 y 1810, años durante los cuales tuvieron mucho peso en los fondos administrados por la real hacienda cuyana. La tendencia es coincidente con lo señalado sobre la hacienda española de Carlos III: el crédito aparece como un recurso extraordinario, limitado a los períodos bélicos a fin de solventar la guerra.

Tomados en conjunto, los aportes del ayuntamiento, los donativos y los préstamos constituyeron un aporte sustancial a la economía de la caja, la cual durante los últimos años coloniales consumió recursos que si bien permitieron capear la conjunción de alza de gastos y caída de recaudación — especialmente entre 1808 y 1810 - eran de muy difícil reposición a futuro.

Las dos últimas tablas con información ilustran lo ocurrido con las cuentas durante el último lustro colonial (tabla n..$^{\circ} 7$ : 1806-1810). Puede constatarse que las alcabalas y los impuestos a la circulación siguieron siendo sustanciales, aunque disminuyeron su importancia en beneficio de otros rubros. Es evidente el peso significativo que asumieron los recursos obtenidos por fuera de la jurisdicción de la Real Hacienda cuyana (suplementos y transfe- 
TABla 7. Ingresos CAJA DE Mendoza 1806-1810

\begin{tabular}{|c|c|c|}
\hline \multicolumn{3}{|c|}{ Ingresos caja real Mendoza - Ultimo lustro colonial 1806-1810 } \\
\hline Alcabalas & 45.585 & $19 \%$ \\
\hline Suplido de tabacos & 33.416 & $14 \%$ \\
\hline Otras tesorerías & 30.000 & $12 \%$ \\
\hline Arbitrios y sisa & 26.459 & $11 \%$ \\
\hline Suplido $\mathrm{x}$ varios interesados & 22.822 & $9 \%$ \\
\hline Depósitos & 13.103 & $5 \%$ \\
\hline De San Juan y San Luis (sin especificar) & 12.848 & $5 \%$ \\
\hline Recibido del Cabildo & 11.358 & $5 \%$ \\
\hline Novenos reales & 10.182 & $4 \%$ \\
\hline $\begin{array}{l}\text { Ramos eclesiásticos (vacantes, expolios, mesadas, herencias, } \\
\text { cruzada, temporalidades) }\end{array}$ & 7.690 & $3 \%$ \\
\hline Bulas en especie recibidas & 5.151 & $2 \%$ \\
\hline Venta de barajas & 4.217 & $2 \%$ \\
\hline Donativos & 3.416 & $1 \%$ \\
\hline Pulperías & 2.972 & $1 \%$ \\
\hline Oficios y cargos (venta y media annata) & 2.162 & $1 \%$ \\
\hline Quinto del oro y estacas de minas & 2.092 & $1 \%$ \\
\hline Nuevo impuesto aguardiente & 1.329 & $1 \%$ \\
\hline Venta papel sellado & 1.323 & $1 \%$ \\
\hline Seguridad social (monte pío militar y ministros, inválidos) & 1.287 & $1 \%$ \\
\hline Venta de Bulas & 917 & $0 \%$ \\
\hline Venta de azogues & 702 & $0 \%$ \\
\hline Venta y arrendamiento de tierras & 391 & $0 \%$ \\
\hline Diezmo y Cobo & 327 & $0 \%$ \\
\hline Penas de Cámara y alcances de cuenta & 309 & $0 \%$ \\
\hline Varios & 2.869 & $1 \%$ \\
\hline Total & 242.927 & $100 \%$ \\
\hline
\end{tabular}

Fuente: elaboración propia en base a las siguientes fuentes consultadas: AGN, Sala XIII, 1102-02 (legajo n. ${ }^{\circ} 15$, libro mayor 1806); 11-02-03 (legajo n. ${ }^{\circ} 16$, libro mayor 1807); 11-02-04 (legajo n. ${ }^{\circ} 17$, libro mayor 1808 y 1809); 11-02-05 (legajo n. ${ }^{\circ} 18$, libro mayor 1810). 
rencia de dinero desde Córdoba) y en particular los mencionados empréstitos tanto de individuos como instituciones, para afrontar el enorme peso de los gastos militares.

En la tabla . $^{\circ} 8$ podemos observar cómo los préstamos y donativos alcanzaron el 16\% de los ingresos del período (entre 1779-1810, apenas la mitad). Pero si a dicho porcentaje le sumamos el 5\% aportado por el Cabildo - incluido en el rubro «suplementos»- en realidad los aportes de terceros representaron el $21 \%$ de su masa de ingresos a fines de la Colonia. Si bien la Real Hacienda virreinal dispuso el envío de fondos en 1807 (30.000 \$ desde Córdoba) para evitar la insolvencia de la caja cuyana, ese monto fue recuperado luego a través de las remesas entre 1808 y abril de 1810 (30.437 \$). Por lo tanto, ante la ausencia de mayores transferencias desde otras tesorerías, la toma de deuda se constituyó en la salida que la administración cuyana encontró a las presiones financieras que acechaban sus cuentas.

TABla 8. Tipos De Ingresos EN \$ y \% PERÍODO 1806-1810

\begin{tabular}{|l|r|r|}
\hline \multicolumn{3}{|c|}{ Ingresos por tipo - Caja real Mendoza 1806-1810 } \\
\hline Comercio y circulación & 76.345 & $31 \%$ \\
\hline Suplementos & 54.142 & $22 \%$ \\
\hline Préstamos y donativos & 39.341 & $16 \%$ \\
\hline Transferencias recibidas & 30.000 & $12 \%$ \\
\hline Administración & 11.448 & $5 \%$ \\
\hline Producción agraria & 10.182 & $4 \%$ \\
\hline Minería & 3.121 & $1 \%$ \\
\hline Ventas & 2.631 & $1 \%$ \\
\hline Otros & 15.717 & $6 \%$ \\
\hline Total ingresos & $\mathbf{2 4 2 . 9 2 7}$ & $\mathbf{1 0 0} \%$ \\
\hline
\end{tabular}

Fuente: elaboración propia en base a fuentes consultadas (ver tabla n. ${ }^{\circ}$ 7).

Uno de los aspectos más preocupantes para la administración lo constituía la deteriorada situación tributaria: la caída de la recaudación genuina era marcada desde 1808 en adelante. Más preocupante era la perspectiva de la caja de Mendoza si se considera su solvencia financiera a comienzos del período independiente. A fines del turbulento año de 1810, el dinero fruto de la 
recaudación (30.225\$, propia y de tabacos) no lograba cubrir la sumatoria de gastos propios y deudas por vencer. Ésta última, que ascendía a 9.105 \$, se hallaba compuesta por los préstamos a devolver al Cabildo y a particulares (3.683 \$ y $5.422 \$$ ). La información contenida en la tabla $n .^{\circ} 8$ confirma esta perspectiva: durante el último quinquenio colonial, los suplementos/transferencias y préstamos/donativos representaron el 50\% de los ingresos de la caja.

En diciembre de 1810 la deuda equivalía a un 30\% de la recaudación anual $\mathrm{y}$ a un $45 \%$ de los saldos (líquidos y en especie). Si bien los números no resultaban alarmantes, la tendencia al crecimiento del endeudamiento no brindaba perspectivas de desacelerarse: la caída de la recaudación y la incierta situación de los estancos reales luego de mayo de 1810 delineaban un escenario a futuro en el cual la tesorería cuyana probablemente necesitaría con mayor ahínco la contribución del Cabildo y de los particulares.

\section{CONCLusiones}

El repaso por la información contenida en los libros mayores y manuales de la caja cuyana permite poner el acento sobre algunos aspectos de la estructura de gastos e ingresos y en especial sobre las salidas de fondos desde la misma hacia la tesorería general del Virreinato, principal objeto de nuestro análisis.

En primer lugar, cabe destacar que dentro de los ingresos de la caja cuyana cobraron protagonismo los vinculados a la circulación mercantil. Principalmente las alcabalas de Mendoza, San Juan y San Luis, pero también los Arbitrios y Sisa, entre otras gabelas, alimentaron los renglones principales de recursos con los que contaba la hacienda regional. En segundo lugar, los suplementos y transferencias recibidas en la tesorería constituyeron un flujo de recursos significativo. Las ventas de azogues, bulas y papel sellado en especie engrosaron las cuentas de la caja. Pero fue particularmente la administración de tabacos y naipes la que incrementó los números del «cargo» de la hacienda mendocina: la política fiscal borbónica determinó regulares traspasos que permitieron hacer frente a los ingentes gastos que se debían afrontar. En menor proporción, también la producción agrícola y minera aportó gruesos fondos, evidenciando el peso de la agricultura mendocina y de la minería de plata y oro en toda la región cuyana. Durante los años finales de la colonia, los aportes de terceros - ya fuera en forma de donativos o préstamos, de personas e instituciones - fueron ocupando un lugar cada vez más significativo en la estructura de ingresos.

En cuanto a los gastos, la principal erogación la constituyó el vinculado al mantenimiento de la frontera sur, tanto en los destinados a la coacción 
militar como a raciones a «indios amigos». El otro renglón significativo de egresos lo constituyó el militar, que se fue incrementando notablemente hacia el final del período, fruto del aumento de la conflictividad en el Río de la Plata especialmente a partir de 1806. Los salarios y traslados de tropa, mantenimiento de prisioneros ingleses y el pago a proveedores constituyeron las erogaciones centrales del rubro. Como tuvimos oportunidad de analizar, el balance de los ingresos y egresos genuinos de la caja cuyana (es decir sin suplementos, préstamos ni envío de remesas) mostró en general saldos favorables durante los años analizados. La Real Hacienda mendocina constituyó una administración que, salvo en algunos pocos años, mostró la capacidad de poder responder a sus erogaciones con fondos propios.

Sin embargo, esta virtual solvencia fue deteriorándose a medida que la etapa colonial llegó a su fin, mostrando la eficacia del sistema de transferencias de recursos que permitió a la administración de hacienda de la capital drenar los saldos existentes en la caja. Si bien los oficiales reales contaron con cierto margen de maniobra para retener saldos líquidos, las urgencias del erario parecieron recortar esa libertad relativa durante la última década: los fondos acumulados, crecientes entre 1795 y 1802, fueron sistemáticamente conducidos hacia la tesorería general entre 1798 y 1804 . Aunque no es posible asegurar que los fondos hayan seguido su camino hacia la península, los datos aportados sí permiten afirmar que la Real Hacienda virreinal logró hacerse con un mayor volumen de divisas provenientes de la caja cuyana, evidenciando una significativa capacidad de extracción de recursos.

De modo similar, las remesas giradas entre 1807 y 1810 redujeron los saldos atesorados durante el último lustro. Entre ambos momentos una diferencia resulta sustancial: durante el primero la exacción buscó drenar una acumulación de fondos que era resultado de una combinación entre buena performance recaudatoria y gastos relativamente estables. En cambio, durante el segundo la extracción de divisas buscó recuperar el auxilio que en 1807 se realizó desde Córdoba para afrontar los ingentes gastos de guerra, dadas las urgencias presupuestarias que atravesaba la hacienda virreinal hacia el final de la década. Hasta los últimos días del vínculo colonial el sistema de transferencias mostró su vitalidad: el último envío de remesas a la capital data del 30 de abril de 1810.

Huelga señalar entonces que el último quinquenio colonial configuró un escenario más que complicado para la tesorería regional: la combinación entre el declive de la recaudación desde 1808, la devolución de los fondos inyectados en 1807 y el aumento de los gastos de guerra a partir de 1805 deterioró las cuentas de la caja. La solución encontrada por los oficiales de hacienda fue el recurso a empréstitos y contribuciones: tanto los donativos, 
como los préstamos de particulares y del Cabildo acrecentaron su peso durante los últimos años coloniales. La hacienda cuyana comenzó entonces su itinerario en la segunda década del siglo XIX con una agenda preocupante: revertir la tendencia a la baja evidenciada por la recaudación a fin de aliviar el peso que los empréstitos comenzaban a ejercer sobre las cuentas y la disponibilidad de fondos, que se redujeron desde 1808 gracias a la eficacia del sistema de transferencias coloniales.

\section{BIBLIOGRAFÍA}

Amaral, Samuel, "Public expenditure financing in the colonial treasury: an analysis of the Real Caja de Buenos Aires accounts, 1789-1791", Hispanic American Historical Review, 64/2 (Durham, 1984): 287-295.

Amaral, Samuel, "Las finanzas arcaicas: la atención del déficit fiscal en la real caja de Buenos Aires, 1789-1811”, Investigaciones y ensayos, 60 (Buenos Aires, 2014): 381-436.

Biangardi, Nicolás, "Financiamiento y distribución del gasto en la caja real de Maldonado (Río de la Plata) 1782-1806", América Latina en la Historia Económica, (México, mayo-agosto 2016): 7-35.

Camarda, Maximiliano, La región Río de la Plata y el comercio ultramarino durante las últimas décadas del siglo XVIII: actores, circulación comercial y mercancías, Universidad Nacional de La Plata, tesis doctoral inédita, 2015.

Comadrán Ruiz, Jorge, "Los subdelegados de Real Hacienda y Guerra de Mendoza (1784-1810)", Revista del Instituto de Historia del derecho, 10 (Buenos Aires, 1960): 82-111.

Conteras, Carlos, "La reforma fiscal de 1815: las finanzas peruanas en vísperas de la independencia", Revista Economía, 50 (Lima, 2002): 123-148.

Cuesta, Martín, "Impuestos imperiales: la Caja Real de Buenos Aires (1700-1800)", Temas de historia argentina y americana, 14 (Buenos Aires, 2009): 27-56.

Flores Guzmán, Ramiro, "Los situados peruanos: desde Chile hasta Panamá, 17001800", Carlos Marichal y Johanna Von Grafenstein (coords.), El secreto del imperio español: los situados coloniales en el siglo XVIII, México, El Colegio de México, Instituto Mora, 2012: 33-60.

Galarza, Antonio Facundo, "La fiscalidad en el Río de la Plata tardocolonial: un posible balance historiográfico a partir de las Cajas Reales", Bibliographica Americana. Revista Interdisciplinaria de Estudios Coloniales, 11 (Buenos Aires, 2015): 9-30. 
Grafenstein, Johanna Von, "Situado y gasto fiscal: la Real Caja de México y las remesas para gastos militares en el Caribe, 1756-1783", Ángelo Alves Carrara y Ernest Sánchez Santiró, Guerra y fiscalidad en la Iberoamérica colonial (siglos XVII-XIX), México, Ed. UFJF/Mora, 2012: 115-142.

Halperín Donghi, Tulio, Guerra y finanzas en los orígenes del Estado argentino (1791-1850), Buenos Aires, Ed. de Belgrano, 1982.

Hamilton, Earl, El tesoro americano y la revolución de los precios en España, 15011650, Barcelona, Crítica, 2000 [1962].

Haring, Clarence, Comercio y navegación entre España y las Indias en la época de los Habsburgo, México, FCE, 1979 [1939].

Irigoin, Alejandra y Grafe, Regina, "The Spanish empire and its legacy: fiscal re-distribution and political conflict in colonial and post-colonial Spanish America", Working papers of the Global Economic History Network (GEHN), 23 (Londres, 2006): 1-63.

Klein, Herbert, "Las finanzas del Virreinato del Río de la Plata en 1790", Desarrollo Económico, 13/50 (Buenos Aires, 1973): 369-400.

Klein, Herbert, "Public expenditures financing in the colonial treasury", Hispanic American Historical Review, 64/2 (Durham, 1984): 310-312.

Klein, Herbert, The American finances of the Spanish empire: royal income and expenditures in colonial Mexico, Peru and Bolivia, 1680-1809, Mexico, University of New Mexico Press, 1998.

Klein, Herbert, "Las finanzas Reales", AA.VV., Nueva Historia de la Nación Argentina. La Argentina en los siglos XVII y XVIII, Buenos Aires, Planeta, 1999, tomo III: $12-30$.

Marichal, Carlos, "La economía de la época borbónica al México independiente, 1760-1850", Sandra Kuntz (coord.), Historia económica general de México. De la Colonia a nuestros días, México, El Colegio de México, 2010: 173-209.

Marichal, Carlos y Rodríguez Venegas, Carlos, La bancarrota del virreinato. Nueva España y las finanzas del Imperio español, 1780-1810, México, FCE/El Colegio de México, 1999.

Marichal, Carlos y Grafenstein, Johanna Von (coords.), El secreto del imperio español: los situados coloniales en el siglo XVIII, México, El colegio de México/ Instituto Mora, 2012.

Meisel, Adolfo, "Crecimiento a través de los subsidios: Cartagena de Indias y el situado, 1751-1810”, Cuadernos de Historia Económica y Empresarial, 9 (Cartagena, 2002): 1-26.

Mira, Guillermo y Gil Lázaro, Alicia, "Minería, comercio y moneda en un período de transición. Potosí, la crisis colonial y las bases del crecimiento económico del Río 
de la Plata después de la Independencia", Alejandra Irigoin y Roberto Schmit (eds.), La desintegración de la economía colonial, Buenos Aires, Ed. Biblos, 2003: 37-56.

Morineau, Michel, Incroyables gazettes et fabuleux métaux. Les retours des trésors américains d'après les gazettes hollandaises (XVIe-XVIIIe siècles), Paris/Londres, Éditions de la Maison des Sciences de l'Homme/Cambridge University Press, 1985.

Moutoukias, Zacarías, Contrabando y control colonial en el siglo XVII: Buenos Aires, el Atlántico y el espacio peruano, Buenos Aires, CEAL, 1988.

Palomeque, Silvia, "Circuitos mercantiles de San Juan, Mendoza y San Luis. Relaciones con el «interior argentino", Chile y el Pacífico sur (1800-1810)», Anuario IEHS, 21 (Tandil, 2006): 255-285.

Santos Martínez, Pedro, Historia económica de Mendoza durante el Virreinato (17761810), Madrid, Universidad Nacional de Cuyo/Instituto Gonzalo Fernández de Oviedo, 1961.

Sovarzo, José, "La garganta del comercio interoceánico. Río de la plata, Mendoza y Santiago de Chile y sus relaciones comerciales a fines del siglo XVIII", IV Jornadas de Historia Económica (Rosario, octubre 2014): 1-28.

Tepaske, John y Klein, Herbert, The royal treasuries of the Spanish empire in America, Durham, Duke University Press, 1982-1990, 4 vols.

Torres Sánchez, Rafael, El precio de la guerra. El Estado fiscal-militar de Carlos III (1779-1783), Madrid, Ed. Marcial Pons, 2013.

Wayar, Alejandro, "Las remesas fiscales intra-coloniales. Una aproximación desde las cajas del Tucumán. 1759-1808", V Jornadas uruguayas de Historia Económica (Montevideo, noviembre 2011): 1-29.

Wasserman, Martín, "Real Situado y gestión patrimonial del recurso fiscal. Remesas para defensa del puerto de Buenos Aires en el siglo XVII", Nuevo Mundo Mundos Nuevos, EHESS (París, 2016), disponible en: http://nuevomundo.revues.org/69317.

Fecha de recepción: 16 de febrero de 2017.

Fecha de envío de las modificaciones: 23 de mayo de 2017.

Fecha de aceptación: 24 de mayo de 2017. 


\section{Raising revenue within the confines of the empire: taxes and remittances in the Caja Real de Mendoza (Río de la Plata) at the end of the colonial period, 1779-1810}

This article presents the findings of research into the tax structure of the "Caja Real de Mendoza" (Rio de la Plata) at the end of the colonial era. The evolution of tax collection and the supplements and transfers received by the local administration are studied, and expenditure structure is characterized. Special attention is paid to the volume of remittances sent from the Caja to the Buenos Aires treasury, in order to estimate the capacity of the capital's Royal Treasury to extract resources from viceregal interior jurisdictions. The aim is to contribute to characterization of the relative success / failure of the imperial tax system at the end of the eighteenth century with regard to collecting taxes and transferring remittances in line with the needs of the Spanish Monarchy.

KeY WORDS: taxes; remittances; Mendoza; Monarchy. 